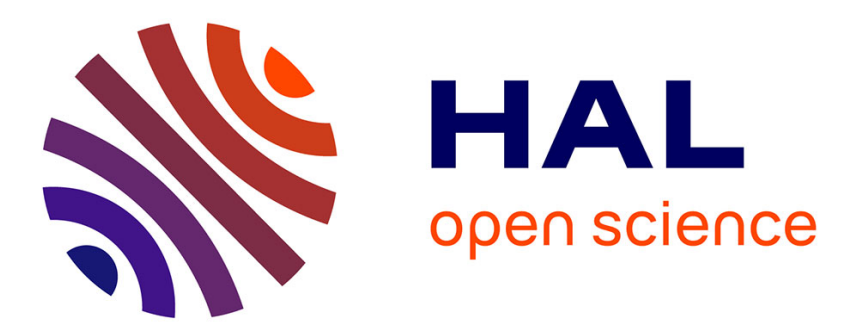

\title{
Freight transportation service procurement: A literature review and future research opportunities in omnichannel E-commerce
}

\author{
Mariam Lafkihi, Shenle Pan, Eric Ballot
}

\section{- To cite this version:}

Mariam Lafkihi, Shenle Pan, Eric Ballot. Freight transportation service procurement: A literature review and future research opportunities in omnichannel E-commerce. Transportation Research Part E: Logistics and Transportation Review, 2019, 125, pp.348-365. 10.1016/j.tre.2019.03.021 . hal02086154

\section{HAL Id: hal-02086154 \\ https://hal.science/hal-02086154}

Submitted on 22 Oct 2021

HAL is a multi-disciplinary open access archive for the deposit and dissemination of scientific research documents, whether they are published or not. The documents may come from teaching and research institutions in France or abroad, or from public or private research centers.
L'archive ouverte pluridisciplinaire HAL, est destinée au dépôt et à la diffusion de documents scientifiques de niveau recherche, publiés ou non, émanant des établissements d'enseignement et de recherche français ou étrangers, des laboratoires publics ou privés.

\section{(ㄷ)(1) $\$$}

Distributed under a Creative Commons Attribution - NonCommerciall 4.0 International 


\section{Freight Transportation Service Procurement: A literature review and future research opportunities in Omnichannel E-commerce}

Mariam Lafkihi

mariam.lafkihi@mines-paristech.fr

Physical Internet Chair

Centre de Gestion Scientifique - I3 - UMR CNRS 9217

MINES ParisTech, PSL Research University

60 boulevard Saint-Michel, 75006, Paris, France

\section{Shenle Pan (Corresponding author)}

shenle.pan@mines-paristech.fr

Physical Internet Chair

Centre de Gestion Scientifique - I3 - UMR CNRS 9217

MINES ParisTech, PSL Research University

60 boulevard Saint-Michel, 75006, Paris, France

\section{Eric Ballot}

eric.ballot@mines-paristech.fr

Physical Internet Chair

Centre de Gestion Scientifique - I3 - UMR CNRS 9217

MINES ParisTech, PSL Research University

60 boulevard Saint-Michel, 75006, Paris, France 


\title{
Freight Transportation Service Procurement: A literature review and future research opportunities in Omnichannel E-commerce
}

\begin{abstract}
This paper provides a literature review of freight transportation service procurement and investigates the challenges and opportunities regarding transportation organization and procurement mechanism design in the context of E-commerce. A total of 78 articles published in academic journals between 1998 and 2017 were reviewed. A framework comprising seven classification criteria is proposed to analyze the articles. The results reveal that new business environments challenge the efficiency and effectiveness of the current leading procurement mechanisms. This work also identifies the trends and gaps from the viewpoints of practitioners and researchers and describes future prospects in new freight transportation markets and organizations.
\end{abstract}

Keywords: Freight transportation service procurement, Online-to-offline E-commerce, Omnichannel, Mechanism design, Literature review, Auction.

\section{Introduction}

The importance of freight transportation is amplified today by the rapid boom in E-commerce, and in particular new online-to-offline $(\mathrm{O} 2 \mathrm{O})$ or omnichannel retailing business strategy (Verhoef et al., 2015; Savelsbergh and Van Woensel, 2016; Hübner et al., 2016a; Hübner et al., 2016b). Moreover, to boost competitiveness, e-tailers and logistics service providers have devoted adequate efforts to managing express fulfilment services, e.g., same-day delivery service (one or two-hour delivery), and various distribution and delivery channels (Savelsbergh and Van Woensel, 2016). This has resulted in massive, high-frequency shipments with short lead times and fluctuating volumes. In China, for instance, over 30 billion packages were delivered across the country in 2016, which is 53\% more than in 2015 (data from the National Bureau of Statistics of China 2018). On 11 November 2018, the E-commerce festival in China generated more than 1 billion packages within only 24 hours, which is approximately 1/30 of the entire year. As a result, transportation costs have been increasing for both long-haul transportation and last-mile delivery (Hübner et al., 2016a).

Moreover, the performance of freight transportation is becoming increasingly crucial to the sustainability of logistics and Supply Chain. On the one hand, freight transportation is the 
largest component of logistics costs for most shippers and can reach $60 \%$ of the total logistics costs of a firm as stated in Collignon (2016). Cost-efficiency in transportation is thus highly sensitive to logistics costs. On the other hand, the current state of freight transportation is not sufficiently optimized and, therefore, is characterized by economic, social and environmental inefficiency and unsustainability. Despite efforts by transport companies, the frequency of empty trips remains high and average truck fill-rate is low. Overall, according to Eurostat (2017), at total transport level, most trucks in Europe fell in the range between $15 \%$ and $30 \%$ empty journeys. Moreover, freight transportation (in developed countries) is responsible for nearly $15 \%$ of greenhouse gas emissions. This ratio has been increasing despite ambitious reduction targets, see International Energy Agency (2017). Improve freight transportation efficiency is therefore crucial to reduce logistics cost, as well as other negative environmental and social externalities.

To improve freight transportation efficiency, the main research stream is applying Operations Research approaches to optimize transport operations, e.g., distribution network design, vehicle routing, transport planning. However, the appropriateness of the freight transportation service procurement (FTSP) mechanism also significantly affects the efficiency and effectiveness of freight transport operations (Caplice, 2007; Xu and Huang, 2013). But the problem has received relatively much less attention. The significance of FTSP can be understood from two evidences of freight market. On the one hand, the variety of procurement mechanisms available in today's freight transport markets, in theory or in practice, shows that there is no single best solution for all FTSP problems, e.g., combinatorial auctions, private or public exchanges, and electronic catalogs (Caplice, 2007). Applying a "well-known mechanism" may be very successful for one situation but totally fail for another with regards trading quantity, means utilization, service rate, etc. Selection of the appropriate transportation procurement mechanism is worth investigating. On the other hand, the rapid evolution of the freight transport market requires guidance and guidelines for mechanism design and its applications. For example, spot markets have been increasing as more and more shippers are looking for short-term or one-shot services for their on-demand transportation requests, in particular regarding less-than-truckload (LTL) or parcel shipments (see some online platforms such as uship.com, anyvan.com). To have a comprehensive review of the state of the art, it was necessary to conduct a systematic review of recent research and applications on FTSP mechanisms. A relevant review has been found in the literature (Jothi Basu et al., 2015). However, the study only focuses on auction mechanisms for the Full 
Truck Load (FTL) sector. To the best of knowledge, no exhaustive and comprehensive review article on FTSP mechanisms can be found in the literature.

Motivated by the research objectives and gaps in the literature, our research aims to exhaustively investigate all existing FTSP mechanisms for different transportation modes and sectors, as well as recent theoretical and practical developments. It is worth mentioning that mechanism design has been studied considerably in other fields including computer science (Nisan, 2007; Parsons et al., 2011) and economics (Klemperer, 1999; Abdulkadiroğlu and Sönmez, 2003). However, this paper focuses on a very different field that is logistics and transportation. This paper firstly focuses on reviewing the recent relevant literature to show to what extent researchers have investigated the problem. To this end, we followed the guidance on writing literature review paper in Wee and Banister (2016), for the organization and structure of the paper. For the review methodology, we adapted the systematic literature review (SLR) methodology discussed in Durach et al. (2017) and in Koufteros et al. (2018). We thus attempt to identify research trends and gaps related to FTSP mechanisms and the applications in real-world cases, as well as to explore new research interests and perspectives in E-commerce. This review target both academia and practitioners.

The paper is organized as follows. Section 2 presents the problem statement in this paper. Section 3 describes the SLR methodology used in this work. Section 4 is dedicated to the main results and findings identified from the survey. Section 5 aims to identify some promising research lines and prospects in order to develop a research agenda for FTSP in Ecommerce. Finally, Section 6 concludes this work.

\section{Research Problem Statement}

This section aims to explain why and how FTSP is related to omnichannel E-commerce. To better illustrate the relevance, a conceptual model is presented here (see Figure 1). 


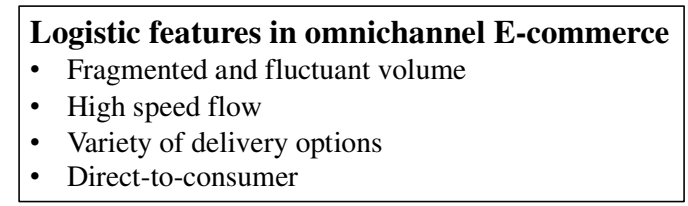

Current challenges in freight market

- Shortage of drivers

- Low margin

- Fierce competition

- Strict constraints and regulations

Innovative models in transportation

- Sharing economies, crowdshipping

- Horizontal cooperation

- Dynamic delivery systems

- Online marketplace

\begin{tabular}{|l|}
\hline Challenges to procurement mechanism \\
- \\
- Short-term / on-demand services \\
- Vertical win-win solutions \\
- Carrier-carrier cooperation \\
\hline
\end{tabular}

Figure 1. Impact of omnichannel E-commerce on freight transport procurement (based on Savelsbergh and Van Woensel (2016))

The current freight transportation organization has been forced to confront the new challenges from omnichannel E-commerce logistics and from trucking industry. Simply speaking, omnichannel E-commerce can be described as a business strategy that aims at reaching customers by means of a variety of marketing, distribution channels, and touchpoints (Verhoef et al., 2015; Savelsbergh and Van Woensel, 2016). O2O strategy in particular aims at bring online customers to bricks-and-mortar locations. It also involves designing fulfillment channels that mutually improve web-based online and bricks-and-mortar offline sales, e.g. brick-and-click service (Agatz et al., 2008; Hübner et al., 2016a; Paul et al., 2019). The two terms, omnichannel and $\mathrm{O} 2 \mathrm{O}$, are interchangeably used in this paper. To enhance consumer's shopping experience, the strategy relies on fast and direct-to-consumer fulfillment, and multi-channel delivery such as home delivery, pickup points, or auto lockers. As a result, the logistic flows of omnichannel E-commerce are characterized to be fragmented and fluctuant, high speed, and with variable delivery points. These flows are therefore extremely difficult to consolidate in shipments under the traditional freight transportation organization models. On the other hand, recent trends in trucking industry also question the traditional models. Currently, trucking companies are facing many difficulties, such as fiercer international competition, low margin in the industry, in addition 
to demanding services required by shipper and strict regulations imposed by government. Consequently, truck driver shortage is predictable in the next future.

To cope with the challenges, innovative organizational models for freight transportation are recently proposed and investigated by practitioners and researchers. Examples include sharing economies in freight transportation (e.g. ride-sharing or crowd shipping), horizontal cooperation between carriers, real-time dynamic vehicle routing, or online freight marketplaces. The effectiveness and efficiency of such models have already proven in the literature (Andres Figliozzi et al., 2003; Archetti et al., 2016; Wang et al., 2016; Chen et al., 2017; Pan et al., 2019). Nevertheless, the perspectives of freight transportation service procurement (FTSP) mechanism have been rarely addressed.

In general, the FTSP problem involves matching shipper transportation needs with carrier capacities in freight marketplaces (Sheffi, 2004; Song and Regan, 2005; Jothi Basu et al., 2015). This problem can be seen from different standpoints. From a shipper (or carrier) standpoint, the problem is the selection (or supply) of services and the choice of the proper buying (or selling) methods. From a market standpoint, it concerns determining methods and settings that incite shippers to buy (or carriers to sell) services efficiently and effectively. In general, these methods, which specify how the transport market operates and the admissible behavior of its participants, are called FTSP mechanisms (Caplice, 2007). It is worth investigating FTSP mechanisms as they could significantly affect the trading volume and efficiency of the freight market (Xu and Huang, 2013). The problem is even more significant for the new organizational models aforementioned. For example, for online marketplaces and crowd shipping, shippers would prefer short-term even one-shot contract for on-demand services, instead of traditional yearly contract with carriers. Besides, to help carriers cope with the difficulties, win-win solutions for either vertical (shipper-carrier) or horizontal (carrier-carrier) relationship should be considered in procurement mechanisms.

This research is motived by the importance of the FTSP mechanism design problem and the research gap. We are particularly interested in investigating the problem in the context of omnichannel E-commerce, as it is a very important and significant topic in logistics and supply chain. To this end, as the first step of the research, this paper focuses on a comprehensive review of the state of the art of FTSP mechanisms, by addressing some research questions related to the context. After the first literature searching, very few papers investigating FTSP in E- 
commerce were found. We thus have extended the scope to freight transportation sector in general, then to study how the related literature can support research on E-commerce transportation as a specific area. The review scope aims to take the balance between specificity and generality as suggested in Wee and Banister (2016).

\section{Systematic Literature Review}

The review adopts the systematic literature review (SLR) methodology recently studied in Durach et al. (2017) and in Koufteros et al. (2018). According to the references, SLRs commonly comprise six steps: (1) define the research questions and theoretical framework, (2) determine the inclusion/exclusion criteria, (3) locate potentially relevant literature, (4) select the pertinent literature according to the inclusion/exclusion criteria, (5) summarize the literature and refine the initial framework, and (6) report and use the results.

\subsection{Research Questions and Theoretical Framework}

The first step of the SLR is to clearly define the research questions and propose an initial theoretical review framework. This paper aims to address the following research questions:

- What major procurement mechanisms are used in research and in practice in the field of FTSP?

- How will the mechanisms influence market and stakeholder behavior, as well as market efficiency and effectiveness?

- What research methodologies are commonly used to study the performance and impact of the mechanisms?

- What are the main challenges and opportunities for FTSP in the context of O2O Ecommerce and what are the future needs and promising lines of development? 


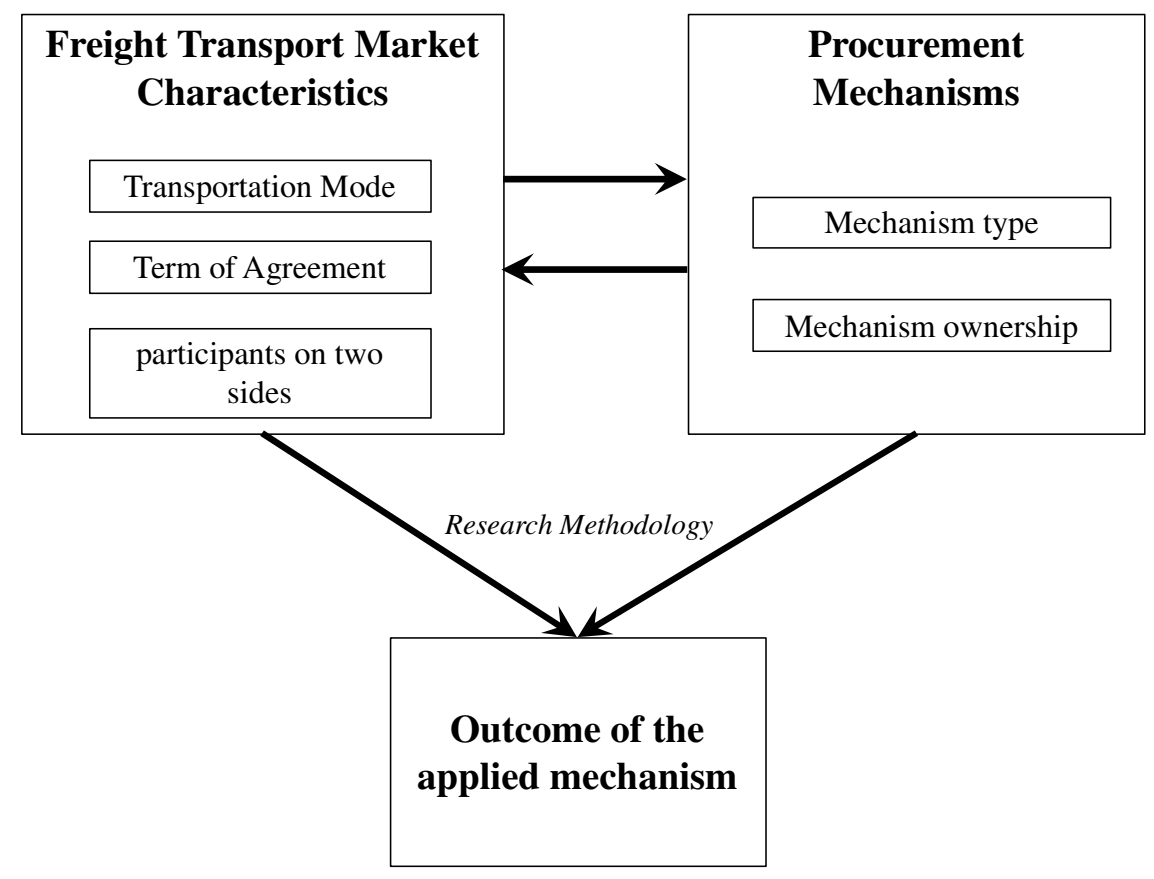

Figure 2. Initial theoretical review framework

With regard to the research questions, we propose an initial framework as shown in Figure 2 that comprises four groups of criteria to categorize the literature. Firstly, we are interested in all procurement mechanisms that are applicable to the freight transportation market and the holders of these mechanisms. Then, according to our expertise and experience, freight transportation markets may vary, especially as regards transportation mode (road, rail, or intermodal, etc.), terms of agreement (long-term, short-term, one shot, etc.), and participants on two sides (many-to-few, many-to-many, etc.). They are generally called market characteristics in the framework. The performance and impact of a mechanism can vary due to the different market characteristics. It is thus significant to study the outcome of the mechanisms regarding either stakeholder or market efficiency. In addition, we are also interested in the methodology used in the literature in order to identify the most common and powerful methodology for the research problem, as well as research trends.

\subsection{Literature Location and Selection}

The steps and criteria to locate and select studies, as well as the reasoning behind each criterion, are presented in Table 1.

\begin{tabular}{ll}
\hline Inclusion \& Exclusion criteria & Reasoning \\
\hline Paper published between 1998 and 2017 (available & Papers published in the past twenty years \\
online included) &
\end{tabular}


Paper published in peer-reviewed academic

journals

Paper written in English

Paper investigating freight transport service procurement mechanisms
To focus on high-quality publications

(Touboulic and Walker, 2015)

English is the dominant language in $\mathrm{SC}$ and logistics research

This is the research problem in this paper

\section{Literature Location}

This step involved two tasks.

- The first step was to locate relevant literature in the field of logistics and transportation in wellknown databases including Springer, Emerald, Science Direct, Informs, Wiley online library, Taylor \& Francis, and JSTOR. We then completed the search with Web of Science, Scopus, and Google Scholar.

- The second step was to define a list of keywords. The main keywords used were "mechanism", "procurement”, "markets", "freight”, "transport(ation)”. In addition, keyword groupings such as "transportation purchasing services", "Freight transportation procurement service mechanisms", "transportation market mechanisms", were used to complete the search. Moreover, to comprehensively cover all mechanisms addressed in literature, the three keywords (negotiation, auction, and catalog) representing the three major mechanisms implemented in transportation markets, according to a previous study (Caplice, 2007), were added. We applied multiple combinations of the keywords in an attempt to find an exhaustive list of all the relevant literature.

\section{Study Selection}

- Using the keywords mentioned above and the databases chosen, 634 articles were located.

- According to the inclusion criteria in Step 1, 409 articles were pre-selected.

- All the remaining articles were saved in the reference management software Endnote in order to review the titles, abstracts, and content and only keep articles in which the clear focus of the research was FTSP mechanisms, including articles comparing and reviewing mechanisms. Finally, 78 articles were selected for review and analysis.

- Other forms of publications such as conference papers, books, reports, theses, are discussed in this paper without being included in the review framework.

Table 1. Study selection steps and criteria (adapted from Durach et al. (2017))

\subsection{Refining the theoretical framework}

The 78 papers selected are classified in Table 4 according to the SLR methodology. After the initial analysis of the selected papers, this section aims to refine the theoretical framework as well as the categorization criteria (Figure 2). 
Procurement mechanism type: Several articles (Nandiraju and Regan, 2005; Caplice, 2007; Collignon, 2016) have classified FTSP mechanisms implemented in trading institutions into three major types: (a) Catalogs (posted prices), wherein carrier offers are posted and the sole choice of the shipper consists in picking the carrier that best fits its own needs. Several markets or platforms such as Iship, Freightquote, and Smartship use this mechanism. (b) Auctions, wherein one party (most often the shipper) posts its requirements and several players in the other party (most often the carriers) place bids. These automated on-line mechanisms such as Uship and Anyvan are widely used in transportation service procurement (TSP). (c) Negotiations, wherein players on both sides of the market, shippers and carriers, bargain over the conditions of an exchange. Several transportation procurement services such as DAT Load Boards, The Internet Truck Stop, and Getloaded use this mechanism.

Procurement mechanism ownership: indicates which of the trading parties manages and defines the rules of the mechanism (e.g., carrier, shipper, or a third party). As stated in Sharifi et al. (2006), the mechanism ownership categories are (a) carrier-owned, (b) shipper-owned, and (c) third-party-owned.

Transportation mode: Transportation systems catering to different transportation modes have proliferated in recent years. The dominant mode is (a) road transportation, which can be further divided into two sectors: Full Truckload (FTL) wherein carriers operate over irregular routes and move from origin to destination without any intermediate stops, and Less Than Truckload (LTL) wherein carriers require the use of terminals and scheduled routes to collect small-sized shipments and consolidate them into larger loads. Moreover, other transportation modes such as (b) railway transportation, (c) air transportation, and (d) maritime transportation are also considered in procurement mechanism design. Some freight marketplaces such as GoCargo (ocean shipping) and Global freight exchange have emerged in recent years.

Terms of agreement: refers to the nature of the contract used in different transportation markets. According to the purpose of the service, there are two major modes of market: (a) spot market, wherein shippers are looking for one-time (one-shot) services for their on-demand transportation requests, and (b) contract market, wherein shippers are seeking to transport their requests over a specific time horizon (i.e., multiple services). 
Participants on two sides: represents the number of participants on each side in the shippercarrier relationship (Wang and Archer, 2007). In literature several categories of shipper-carrier markets are considered: (a) many-to-few for a market with many shippers and few carriers, (b) many-to-many for a market with many shippers and many carriers, and (c) few-to-many for a market with few shippers and many carriers. In this review, the term few includes one, e.g., many-to-few markets include many-to-one markets.

Procurement mechanism outcomes: The FTSP mechanisms impact numerous variables and outcomes, e.g., transaction process, on-time performance, transportation cost, relationships between agents, trust, achievements and satisfaction, ease of use and usefulness, perceived opportunism, etc. These outcomes can be aggregated at two levels: individual outcomes or market outcomes. Individual outcomes contain: Objective Outcomes which include utility value, values of different attributes, and time spent on the transaction, etc., and Subjective Outcomes which include trust, relationships between agents, their achievements and satisfaction, perceived opportunism, etc., while market outcomes include allocation efficiency and social welfare.

Article research methodology: From the articles reviewed, 5 categories of methodology were observed: (a) conceptual analyses which comprise theoretical studies reporting issues and challenges without any numerical or empirical studies, (b) case studies which investigate realworld cases often with data and results, (c) literature reviews, (d) empirical studies based on observed and measured phenomena deriving knowledge from actual experiences rather than from theories or beliefs, and (e) numerical experiments which involve studying approximation techniques for solving problems.

\section{Results and Key Findings}

This section aims to analyze the literature according to the distribution of the papers in different journals over time and the different authors. All papers selected were positioned according to the categorization criteria presented in the initial framework. This classification will allow us to determine the areas of major interest to date and the areas where research gaps are evident. 


\subsection{Descriptive analysis}

\subsubsection{Publications by year}

Based on the 78 articles selected, the first observation is that the number of publications has been increasing in recent years, with 36 papers published in the last 5 years (see Figure 3 ) and only two papers published between 1998 and 2002. This trend reflects the increasing interest in research on innovative mechanisms and guidelines for mechanism design, stimulated by recent rapid changes in freight transportation markets and the emergence of new freight markets.

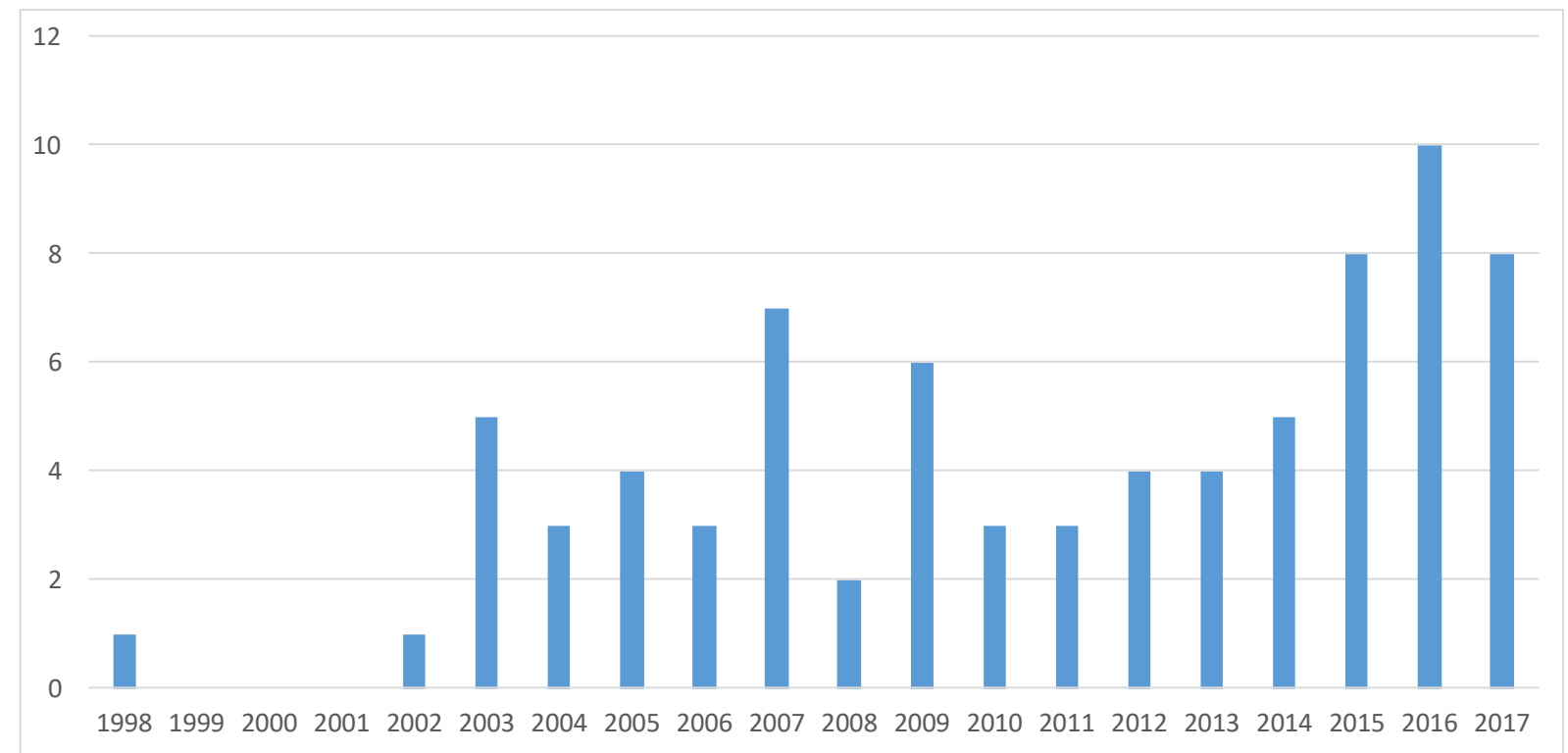

Figure 3. Distribution of articles per year

\subsubsection{Publications by journal}

The 78 articles selected were published in 35 different international journals in the field of logistics and transportation, and particularly in Management Science and Operation Research. Six journals account for almost half of the articles (see Table 2), while the remaining articles were published in 29 different journals. Three journals made special contributions: Transportation Research Part B: Methodological published the most articles, followed by Transportation Research Part E: Logistics and Transportation Review, and Transportation Research Record: Journal of the Transportation Research Board.

\begin{tabular}{lcc}
\hline Journals & Number of papers & Percentage \\
\hline Transportation Research Part B: Methodological & 11 & $14,10 \%$ \\
Transportation Research Part E: Logistics and Transportation Review & 9 & $11,54 \%$ \\
Transportation Research Record: Journal of the Transportation Research & 6 & $7,69 \%$ \\
European Journal of Operational Research & 5 & $6,41 \%$ \\
Transportation Science & 5 & $6,41 \%$ \\
Interfaces & 3 & $3,85 \%$ \\
Computers \& Industrial Engineering & 2 & $2,56 \%$ \\
Computers \& Operations Research & 2 & $2,56 \%$
\end{tabular}


Journal of Intelligent Manufacturing

Journal of Operations Management

Journal of the Operational Research Society

OR Spectrum

Production and Operations Management

Transportation Research Part C: Emerging Technologies

Transportation Research Procedia

European Journal of Operational Research

Annals of Operations Research

Decision Analysis

Decision Support Systems

Expert Systems with Applications

Industrial Marketing Management

Information Systems and e-Business Management

Journal of Business Logistics

Journal of Environmental Economics and Management

Journal of Rail Transport Planning \& Management

Logistics Research

Marketing Science

Networks and Spatial Economics

Omega-International Journal of Management Science

The International Journal of Logistics Management

Table 2. Distribution of articles in journals

\subsubsection{Publications by author}

Table 3 represents the top ten contributing authors and the number of contributions in the field of FTSP mechanisms. Su Xiu Xu and George Q. Huang from the University of Hong-Kong have been the most productive in this field with 8 and 6 papers, respectively. The next most prolific have been Mahmassani Hani with 6 publications, and Jaillet Patrick, Lim Andrew, and Figliozzi Miguel with 5 publications each.

\begin{tabular}{lll}
\hline Authors & Number of contributions & Percentage \\
\hline Su Xiu Xu & 8 & $10,39 \%$ \\
George Q. Huang & 6 & $7,79 \%$ \\
Mahmassani Hani & 6 & $7,79 \%$ \\
Jaillet Patrick & 5 & $6,49 \%$ \\
Lim Andrew & 5 & $6,49 \%$ \\
Figliozzi Miguel & 5 & $6,49 \%$ \\
Chen Haoxun & 4 & $5,19 \%$ \\
Meng Cheng & 3 & $3,90 \%$ \\
Regan Amelia & 3 & $3,90 \%$ \\
Triki Chefi & 3 & $3,90 \%$ \\
\hline
\end{tabular}

Table 3. Ten leading authors in the field 


\subsection{Categorization analysis}

This section reports the key findings from the literature review. Derived from the categorization criteria, the discussion is based mainly on one table and two figures. Table 4 shows the classification of the papers studied according to the categorization criteria. Figure 4 shows the distribution of the literature according to the categorization criteria. Figure 5 shows the number of papers per classification criterion and per period of 5 years, i.e., 1998-2002, 2003-2007, 2008-2012, and 2013-2017.

\begin{tabular}{|c|c|c|}
\hline \multicolumn{3}{|c|}{ The procurement mechanisms } \\
\hline \multirow[t]{3}{*}{$\begin{array}{l}\text { Mechanism } \\
\text { type }\end{array}$} & Auction & $\begin{array}{l}\text { (Ağrall et al., 2008), (Alp et al., 2003), (Andres Figliozzi et al., 2003), (Jothi Basu et al., 2017), (Berger } \\
\text { agn Bierwirth, 2010), (Buer and Kopfer, 2014), (Buer and Pankratz, 2010), (Caplice, 2007), (Caplice and } \\
\text { Sheffi, 2003), (Carter et al., 2004), (Carter and Stevens, 2007), (Chang, 2009), (Chen, 2016), (Chen et al., } \\
\text { 2009), (Cheng, 2011), (Cheng et al., 2016), (Dahl and Derigs, 2011), (Figliozzi et al., 2004), (Figliozzi et } \\
\text { al., 2005), (Figliozzi et al., 2006), (Figliozzi et al., 2007), (Gansterer and Hartl, 2016), (Garrido, 2007), } \\
\text { (Gattiker et al., 2007), (Goldsby and Eckert, 2003), (Guo et al., 2006), (Handoko and Lau, 2016), (Hu et } \\
\text { al., 2016), (Huang and Xu, 2013), (Jothi Basu et al., 2015), (Jothi Basu et al., 2015), (Kersten, 2009), (Kuo } \\
\text { and Miller-Hooks, 2012), (Kuo and Miller-Hooks, 2015), (Kuyzu et al., 2015), (Lalive et al., 2017), } \\
\text { (Ledyard et al., 2002), (Lee et al., 2007), (Li and Zhang, 2015), (Li et al., 2016), (Lim et al., 2012), (Lim } \\
\text { et al., 2008), (Lindsey and Mahmassani, 2017), (Ma et al., 2010), (Mes et al., 2009), (Mesa-Arango and } \\
\text { Ukkusuri, 2013), (Özener et al., 2011), (Park and Rothkopf, 2005), (Qiao et al., 2016), (Qin et al., 2012), } \\
\text { (Rekik and Mellouli, 2012), (Remli and Rekik, 2013), (Robu et al., 2011), (Sandholm et al., 2006), } \\
\text { (Schwind et al., 2009), (Sheffi, 2004), (Song and Regan, 2003), (Song and Regan, 2005), (Triki et al., } \\
\text { 2017), (Triki et al., 2014), (van Duin et al., 2007), (Wang and Wang, 2015), (Wang and Kopfer, 2014), } \\
\text { (Wang and Xia, 2005), (Xu and Huang, 2013), (Xu and Huang, 2014), (Xu and Huang, 2017), (Xu et al., } \\
\text { 2015), (Xu et al., 2016), (Zhang et al., 2014), (Zhang et al., 2015), (Zhang et al., 2016) }\end{array}$ \\
\hline & Negotiation & $\begin{array}{l}\text { (Caplice, 2007), (Cheng, 2011), (Gattiker et al., 2007), (Goldsby and Eckert, 2003), (Hedvall et al., 2017), } \\
\text { (Lalive et al., 2017), (Lim et al., 2012), (Lim et al., 2008), (Mes et al., 2009), (Remli and Rekik, 2013), } \\
\text { (Robu et al., 2011), (Song and Regan, 2003), (van Duin et al., 2007) }\end{array}$ \\
\hline & Catalog & (Balasubramanian, 1998), (Caplice, 2007) \\
\hline \multirow{3}{*}{$\begin{array}{l}\text { Mechanism } \\
\text { ownership }\end{array}$} & Carrier-owned & $\begin{array}{l}\text { (Berger and Bierwirth, 2010), (Gansterer and Hartl, 2016), (Kuo and Miller-Hooks, 2012), (Ledyard et al., } \\
\text { 2002), (Li et al., 2016), (Özener et al., 2011), (Park and Rothkopf, 2005), (Wang and Wang, 2015), (Xu } \\
\text { and Huang, 2017) }\end{array}$ \\
\hline & $\begin{array}{l}\text { Shipper- } \\
\text { owned }\end{array}$ & $\begin{array}{l}\text { (Ağralı et al., 2008), (Alp et al., 2003), (Jothi Basu et al., 2017), (Buer and Pankratz, 2010), (Caplice and } \\
\text { Sheffi, 2003), (Carter et al., 2004), (Carter and Stevens, 2007), (Chang, 2009), (Chen et al., 2009), } \\
\text { (Figliozzi et al., 2004), (Figliozzi et al., 2005), (Figliozzi et al., 2006), (Figliozzi et al., 2007), (Gattiker et } \\
\text { al., 2007), (Goldsby and Eckert, 2003), (Hu et al., 2016), (Huang and Xu, 2013), (Kersten, 2009), (Kuyzu, } \\
\text { 2017), (Lee et al., 2007), (Lim et al., 2008), (Ma et al., 2010), (Mes et al., 2009), (Mesa-Arango and } \\
\text { Ukkusuri, 2013), (Remli and Rekik, 2013), (Sandholm et al., 2006), (Sheffi, 2004), (Song and Regan, } \\
\text { 2003), (Song and Regan, 2005), (Triki et al., 2014), (van Duin et al., 2007), (Wang and Kopfer, 2014), } \\
\text { (Zhang et al., 2014), (Zhang et al., 2015) }\end{array}$ \\
\hline & $\begin{array}{l}\text { Third-party- } \\
\text { owned }\end{array}$ & $\begin{array}{l}\text { (Buer and Kopfer, 2014), (Chen, 2016), (Cheng et al., 2016), (Garrido, 2007), (Handoko and Lau, 2016), } \\
\text { (Li and Zhang, 2015), (Lindsey and Mahmassani, 2017), (Wang and Xia, 2005), (Xu and Huang, 2013), } \\
\text { (Xu and Huang, 2014), (Xu et al., 2015), (Xu et al., 2016), (Zhang et al., 2016) }\end{array}$ \\
\hline
\end{tabular}

\section{The market characteristics}

\begin{tabular}{|c|c|c|}
\hline \multirow[t]{4}{*}{$\begin{array}{c}\text { Transportation } \\
\text { mode }\end{array}$} & Road & $\begin{array}{l}\text { (Ağralı et al., 2008), (Alp et al., 2003), (Andres Figliozzi et al., 2003), (Jothi Basu et al., 2017), (Berger } \\
\text { and Bierwirth, 2010), (Buer and Kopfer, 2014), (Buer and Pankratz, 2010), (Caplice, 2007), (Caplice and } \\
\text { Sheffi, 2003), (Carter et al., 2004), (Carter and Stevens, 2007), (Chang, 2009), (Chen, 2016), (Chen et al., } \\
\text { 2009), (Cheng et al., 2016), (Figliozzi et al., 2004), (Figliozzi et al., 2005), (Figliozzi et al., 2006), (Figliozzi } \\
\text { et al., 2007), (Gansterer and Hartl, 2016), (Garrido, 2007), (Goldsby and Eckert, 2003), (Guo et al., 2006), } \\
\text { (Handoko and Lau, 2016), (Hedvall et al., 2017), (Hu et al., 2016), (Huang and Xu, 2013), (Jothi Basu et } \\
\text { al., 2015), (Kersten, 2009), (Kuyzu, 2017), (Kuyzu et al., 2015), (Ledyard et al., , 2002), (Lee et al., 2007), } \\
\text { (Li et al., 2016), (Lim et al., 2008), (Lindsey and Mahmassani, 2017), (Ma et al., 2010), (Mes et all, 2009), } \\
\text { (Mesa-Arango and Ukkusuri, 2013), (Özener et al., 2011), (Park and Rothkopf, 2005), (Qiao et al., 2016), } \\
\text { (Rekik and Mellouli, 2012), (Remli and Rekik, 2013), (Robu et al., 2011), (Sandholmet al., 2006), (Sheffi, } \\
\text { 2004), (Song and Regan, 2003), (Song and Regan, 2005), (Triki et al., 2014), (van Duin et al., 2007), (Wang } \\
\text { and Wang, 2015), (Wang and Kopfer, 2014), (Wang and Xia, 2005), (Xu and Huang, 2013), (Xu and } \\
\text { Huang, 2014), (Xu and Huang, 2017), (Xu et al.,, 2015), (Zhang et al., 2014), (Zhang et al., 2015), (Zhang } \\
\text { et al., 2016) }\end{array}$ \\
\hline & Railway & (Hu et al., 2016), (Kuo and Miller-Hooks, 2012), (Kuo and Miller-Hooks, 2015), (Lalive et al., 2017) \\
\hline & Maritime & (Hu et al., 2016), (Li and Zhang, 2015), (Lim et al., 2012) \\
\hline & Multimodal & (Xu et al., 2015) \\
\hline
\end{tabular}




\begin{tabular}{|c|c|c|}
\hline \multirow[t]{2}{*}{$\begin{array}{l}\text { Terms of } \\
\text { agreement }\end{array}$} & Contract & $\begin{array}{l}\text { (Alp et al., 2003), (Jothi Basu et al., 2017), (Berger and Bierwirth, 2010), (Buer and Kopfer, 2014), (Buer } \\
\text { and Pankratz, 2010), (Caplice, 2007), (Caplice and Sheffi, 2003), (Carter et al., 2004), (Carter and Stevens, } \\
\text { 2007), (Chen, 2016), (Chen et al., 2009), (Cheng, 2011), (Gansterer and Hartl, 2016), (Goldsby and Eckert, } \\
\text { 2003), (Guo et al., 2006), (Hedvall et al., 2017), (Hu et al., 2016), (Huang and Xu, 2013), (Jothi Basu et } \\
\text { al., 2015), (Kersten, 2009), (Kuo and Miller-Hooks, 2015), (Kuyzu, 2017), (Kuyzu et al., 2015), (Lalive et } \\
\text { al., 2017), (Ledyard et al., 2002), (Lee et al., 2007), (Li and Zhang, 2015), (Li et al., 2016), (Lim et al., } 2 \text { an and } \\
\text { 2012), (Lim et al., 2008), (Ma et al., 2010), (Mesa-Arango and Ukkusuri, 2013), (Özener et al., 2011), (Park } \\
\text { and Rothkopf, 2005), (Qin et al., 2012), (Rekik and Mellouli, 2012), (Remli and Rekik, 2013), (Robu et } \\
\text { al., 2011), (Sandholm et al., 2006), (Sheffi, 2004), (Song and Regan, 2003), (Song and Regan, 2005), (Triki } \\
\text { et al., 2014), (van Duin et al., 2007), (Wang and Wang, 2015), (Wang and Kopfer, 2014), (Wang and Xia, } \\
\text { 2005), (Xu and Huang, 2014), (Xu and Huang, 2017), (Xu et al., 2015), (Zhang et al., 2014), (Zhang et al., } \\
\text { 2015), (Zhang et al., 2016) }\end{array}$ \\
\hline & Spot market & $\begin{array}{l}\text { (Ağralı et al., 2008), (Chang, 2009), (Figliozzi et al., 2004), (Figliozzi et al., 2005), (Figliozzi et al., 2006), } \\
\text { (Figliozzi et al., 2007), (Garrido, 2007), (Kuo and Miller-Hooks, 2012), (Kuyzu et al., 2015), (Lindsey and } \\
\text { Mahmassani, 2017), (Mes et al., 2009), (Qiao et al., 2016), (Schwind et al., 2009), (Xu and Huang, 2013), } \\
\text { (Xu and Huang, 2017) }\end{array}$ \\
\hline \multirow{3}{*}{$\begin{array}{l}\text { Participants } \\
\text { on two sides }\end{array}$} & Few-to-many & $\begin{array}{l}\text { (Ağralı et al., 2008), (Alp et al., 2003), (Jothi Basu et al., 2017), (Buer and Pankratz, 2010), (Chang, 2009), } \\
\text { (Cheng, 2011), (Figliozzi et al., 2004), (Figliozzi et al., 2005), (Figliozzi et al., 2006), (Figliozzi et al,, } \\
\text { 2007), (Goldsby and Eckert, 2003), (Hu et al., 2016), (Huang and Xu, 2013), (Lee et al., 2007), (Lim et al,, } \\
\text { 2012), (Lim et al., 2008), (Ma et al., 2010), (Mes et al., 2009), (Remli and Rekik, 2013), (Sandholm et al., } \\
\text { 2006), (Sheffi, 2004), (Song and Regan, 2005), (Wang and Kopfer, 2014), (Zhang et al., 2014) }\end{array}$ \\
\hline & Many-to-few & $\begin{array}{l}\text { (Gansterer and Hartl, 2016), (Kuo and Miller-Hooks, 2012), (Ledyard et al., 2002), (Li and Zhang, 2015), } \\
\text { (Li et al., 2016), (Özener et al., 2011), (Park and Rothkopf, 2005), (Wang and Wang, 2015), (Xu and Huang, } \\
\text { 2017) }\end{array}$ \\
\hline & Many-to-many & $\begin{array}{l}\text { (Andres Figliozzi et al., 2003), (Buer and Kopfer, 2014), (Chang, 2009), (Chen, 2016), (Chen et al., 2009), } \\
\text { (Cheng et al., 2016), (Garrido, 2007), (Guo et al., 2006), (Handoko and Lau, 2016), (Jothi Basu et al,, } \\
\text { 2015), (Kuyzu et al., 2015), (Lalive et al., 2017), (Lindsey and Mahmassani, 2017), (Qiao et al., 2016), } \\
\text { (Schwind et al., 2009), (Wang and Xia, 2005), (Xu and Huang, 2013), (Xu and Huang, 2014), (Xu and } \\
\text { Huang, 2017), (Xu et al., 2015), (Xu et al., 2016), (Zhang et al., 2016) }\end{array}$ \\
\hline \multicolumn{3}{|c|}{ The procurement mechanism outcomes } \\
\hline \multicolumn{2}{|c|}{$\begin{array}{l}\text { Individual Objective } \\
\text { Outcomes }\end{array}$} & $\begin{array}{l}\text { (Ağralı et al., 2008), (Andres Figliozzi et al., 2003), (Carter et al., 2004), (Chang, 2009), (Cheng, 2011), } \\
\text { (Figliozzi et al., 2004), (Figliozzi et al., 2006), (Figliozzi et al., 2007), (Gansterer and Hartl, 2016), (Guo } \\
\text { et al., 2006), (Kuyzu, 2017), (Kuyzu et al., 2015), (Ledyard et al., 2002), (Lee et al., 2007), (Li and Zhang, } \\
\text { 2015), (Li et al., 2016), (Lim et al., 2012), (Ma et al., 2010), (Özener et al., 2011), (Park and Rothkopf, } \\
\text { 2005), (Qiao et al., 2016), (Rekik and Mellouli, 2012), (Sandholm et al., 2006), (Sheffi, 2004), (Song and } \\
\text { Regan, 2003), (Song and Regan, 2005), (Triki et al., 2017), (Triki et al., 2014) }\end{array}$ \\
\hline \multicolumn{2}{|c|}{$\begin{array}{l}\text { Individual Subjective } \\
\text { Outcomes }\end{array}$} & $\begin{array}{l}\text { (Andres Figliozzi et al., 2003), (Jothi Basu et al., 2017), (Berger and Bierwirth, 2010), (Buer and Kopfer, } \\
\text { 2014), (Caplice, 2007), (Caplice and Sheffi, 2003), (Carter and Stevens, 2007), (Figliozzi et al., 2005), } \\
\text { (Gattiker et al., 2007), (Guo et al., 2006), (Hu et al., 2016), (Rekik and Mellouli, 2012), (Sheffi, 2004) }\end{array}$ \\
\hline \multicolumn{2}{|c|}{ Market Outcomes } & $\begin{array}{l}\text { (Ağralı et al., 2008), (Alp et al., 2003), (Andres Figliozzi et al., 2003), , (Berger and Bierwirth, 2010), } \\
\text { (Buer and Kopfer, 2014), (Buer and Pankratz, 2010), (Cheng et al., 2016), (Dahl and Derigs, 2011), } \\
\text { (Garrido, 2007), (Goldsby and Eckert, 2003), (Handoko and Lau, 2016), (Hedvall et al., 2017), (Hu et al,, } \\
\text { 2016), (Huang and Xu, 2013), (Jothi Basu et al., 2015), (Kersten, 2009), (Kuo and Miller-Hooks, 2012), } \\
\text { (Kuo and Miller-Hooks, 2015), (Lalive et al., 2017), (Lim et al., 2008), (Mesa-Arango and Ukkusuri, 2013), } \\
\text { (Schwind et al., 2009), (Song and Regan, 2005), (van Duin et al., 2007), (Wang and Wang, 2015), (Wang } \\
\text { and Kopfer, 2014), (Wang and Xia, 2005), (Xu and Huang, 2013), (Xu and Huang, 2014), (Xu and Huang, } \\
\text { 2017), (Xu et al., 2015), (Xu et al., 2016), (Zhang et al., 2014), (Zhang et al., 2015), (Zhang et al., 2016) }\end{array}$ \\
\hline \multicolumn{3}{|c|}{ The research methodologies } \\
\hline \multicolumn{2}{|c|}{ Conceptual studies } & $\begin{array}{l}\text { (Caplice, 2007), (Caplice and Sheffi, 2003), (Garrido, 2007), (Goldsby and Eckert, 2003), (Lindsey and } \\
\text { Mahmassani, 2017), (Sheffi, 2004) }\end{array}$ \\
\hline \multicolumn{2}{|c|}{ Empirical studies } & (Alp et al., 2003), (Buer and Kopfer, 2014), (Kuyzu et al., 2015), (Park and Rothkopf, 2005), \\
\hline \multicolumn{2}{|c|}{ Case studies } & $\begin{array}{l}\text { (Ağralı et al., 2008), (Jothi Basu et al., 2017), (Carter and Stevens, 2007), (Hedvall et al., 2017), (Lalive et } \\
\text { al., 2017), (Ledyard et al., 2002), (Lim et al., 2012), (Robu et al., 2011), (Sandholm et al., 2006), (Schwind } \\
\text { et al., 2009) }\end{array}$ \\
\hline \multicolumn{2}{|c|}{ Literature reviews } & (Jothi Basu et al., 2015) \\
\hline \multicolumn{2}{|c|}{ Numerical experiments } & $\begin{array}{l}\text { (Andres Figliozzi et al., 2003), (Berger and Bierwirth, 2010), (Buer and Pankratz, 2010), (Chang, 2009), } \\
\text { (Chen, 2016), (Chen et al., 2009), (Cheng, 2011), (Cheng et al., 2016), (Dahl and Derigs, 2011), (Figliozzi } \\
\text { et al., 2004), (Figliozzi et al., 2005), (Figliozzi et al., 2006), (Figliozzi et al., 2007), (Gansterer and Hartl, } \\
\text { 2016), (Garrido, 2007), (Guo et al., 2006), (Huang and Xu, 2013), (Jothi Basu et al., 2015), (Kuo and } \\
\text { Miller-Hooks, 2012), (Kuo and Miller-Hooks, 2015), (Lee et al., 2007), (Li et al., 2016), (Lim et al., 2008), } \\
\text { (Ma et al., 2010), (Mes et al., 2009), (Mesa-Arango and Ukkusuri, 2013), (Özener et al., 2011), (Qiao et } \\
\text { al., 2016), (Qin et al., 2012), (Rekik and Mellouli, 2012), (Remli and Rekik, 2013), (Song and Regan, } \\
\text { 2003), (Song and Regan, 2005), (Triki et al., 2017), (Triki et al., 2014), (Wang and Wang, 2015), (Wang } \\
\text { and Xia, 2005), (Xu and Huang, 2013), (Xu and Huang, 2014), (Xu and Huang, 2017), (Xu et al., 2015), } \\
\text { (Xu et al., 2016), (Zhang et al., 2014), (Zhang et al., 2015), (Zhang et al., 2016) }\end{array}$ \\
\hline
\end{tabular}

Table 4. Classification of papers studied in the literature review 


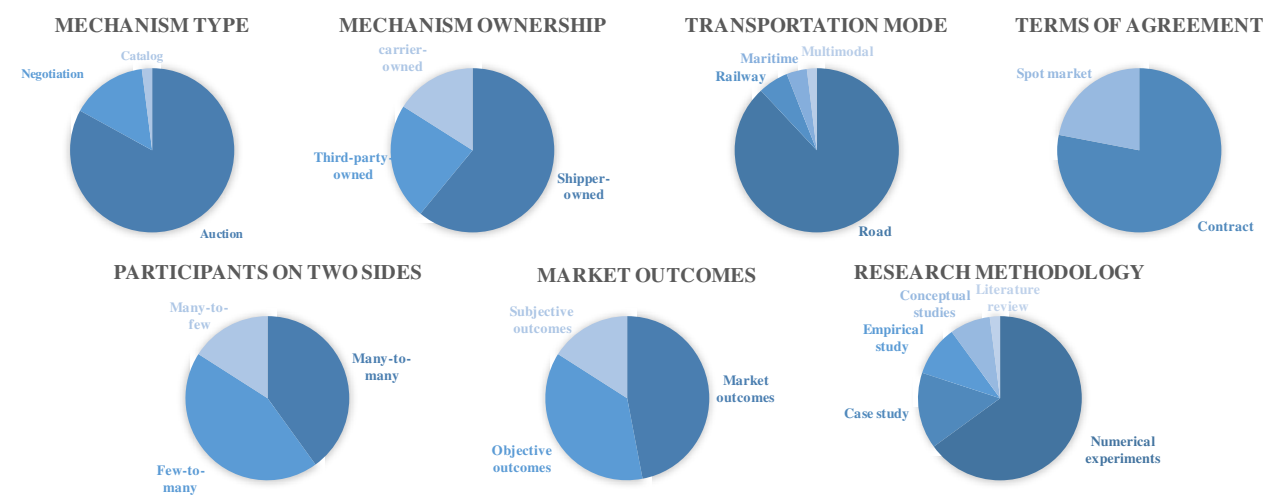

Figure 4. Distribution of papers according to the classification criteria (in percentage)

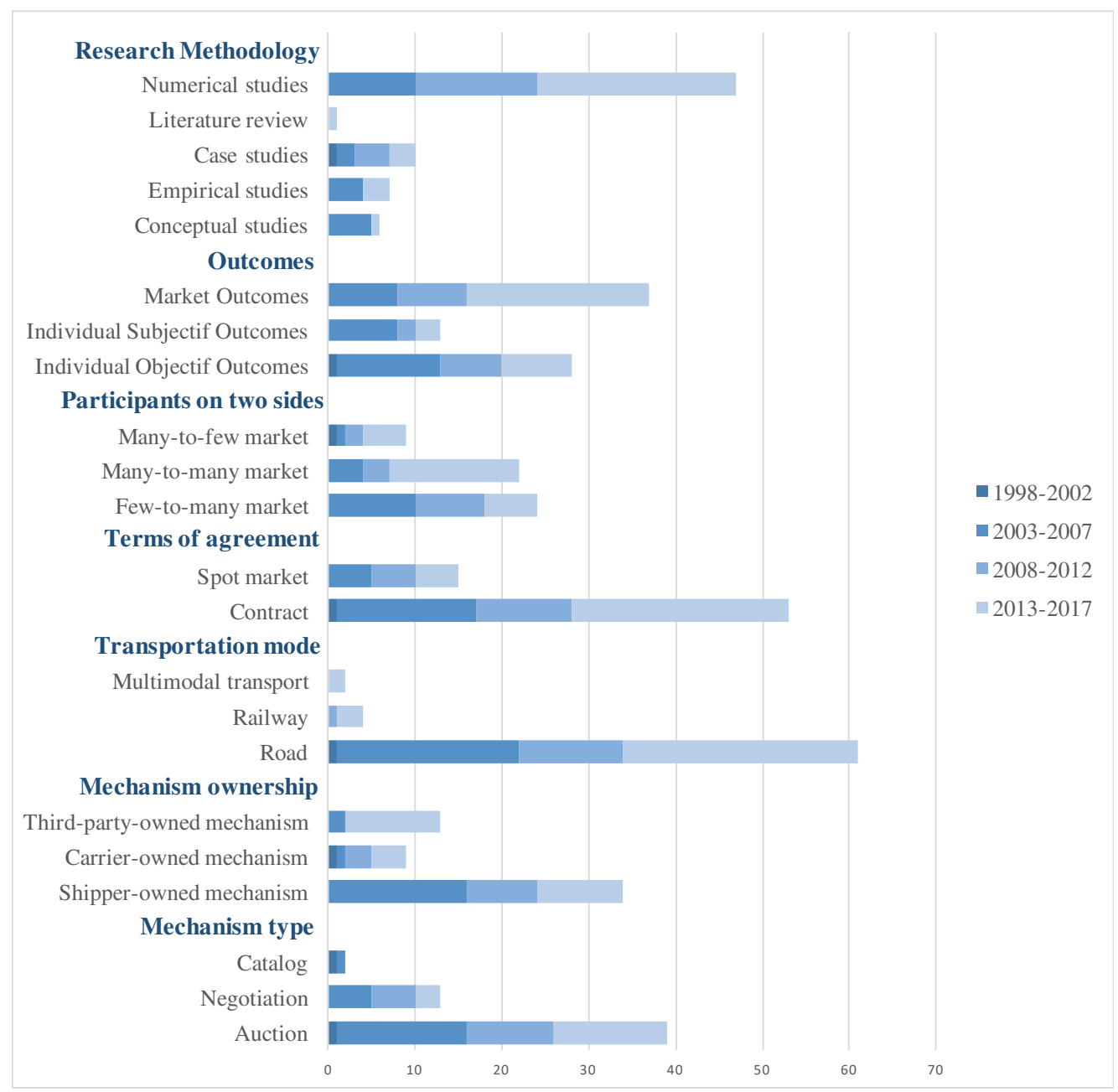

Figure 5. Number of papers per criterion and per period

\subsubsection{Procurement mechanism type}

The first notable conclusion drawn from Table 4 and Figure 4 is that auctions are the mechanism addressed the most by academia $-83 \%$ of articles in this review are dealing with auction mechanisms, while $15 \%$ are dealing with negotiation and only $2 \%$ are dealing with catalogs. 


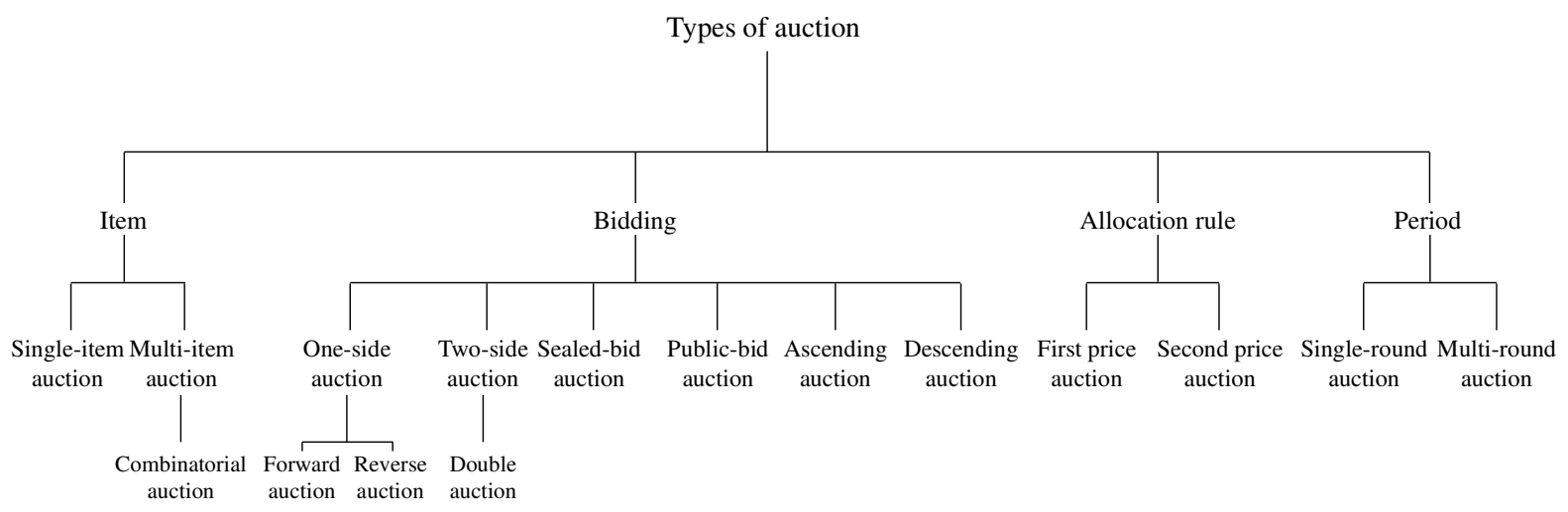

Figure 6. Classification of auction's types in freight transportation literature

Different auction mechanisms have been studied in freight transportation literature. Here we propose a classification framework according to four criteria, that are trading item (single-item, multi-item or combinatorial auctions), bidding strategy (one-side, two-side, sealed-bid, publicbid, ascending or descending auctions), allocation rule (first price or second price auctions), and auction period (single-round or multi-round auctions) (see Figure 6).

Regarding trading item, Caplice and Sheffi (2003) explain that traditionally shippers use singleitem auctions to procure transportation services for a set of lanes (or for an entire region) from a single carrier. Advantages of such mechanism include allowing the carrier to provide coverage during a demand surge, or allowing a simple carrier selection at the operational stage. In last years, the development of technologies used in freight transportation markets allows shippers to use multi-item (or multiunit) auctions wherein they assign more than one carrier to a lane. Similarly, the arise of online marketplaces allows shippers to put all lanes simultaneously online so that carriers can simultaneously bid upon combinations of lanes, i.e. using combinatorial auctions. The pertinence of combinatorial auctions to FTSP is argued in Özener et al. (2011) as they enable synergies between requests/lanes, and particularly for exploiting the economies of scope in transportation as stated in Sheffi (2004). A review of practical issues relating to the execution of combinatorial auctions can be found in Caplice and Sheffi (2003).

Several papers in freight transportation literature have studied different bidding strategies of auction mechanisms. Bidding strategy discussed here involves three questions - who can bid, how to bid, and at what price. One-side auctions mean either buyer or seller can bid. It includes forward auctions wherein shippers (service buyer) bid on carrier's capacities (seller), and reverse auctions in a contrary way. During the last twenty years, reverse auctions have been the dominant research interest, in this field (Ledyard et al., 2002; Song and Regan, 2003; Sheffi, 
2004; Song and Regan, 2005; Figliozzi et al., 2007; Chen et al., 2009). In recent years, researchers have begun to address two-side auctions (also called double auctions) that require both buyer and seller to name price, see Xu and Huang (2013) and Xu and Huang (2014) for example. According to Xu and Huang (2013) and Cheng et al. (2016), the use of double auctions is promising for FTSP, as it allows shippers and carriers to bid simultaneously and to reduce the trading inefficiency. In addition, double auctions could reduce the opportunism perceived with reverse auctions that could lead to a loss of trust. Some other papers have addressed the question of how to bid. For example, carriers as bidders may have visibility of the price submitted by their competitors or not, i.e., sealed-bid auctions or public-bid auctions respectively (Cheng, 2011). Due to information privacy issue, sealed-bid auctions have been the most used in freight transportation markets (Carter et al., 2004; Berger and Bierwirth, 2010; Mesa-Arango and Ukkusuri, 2013; Jothi Basu et al., 2015). The third question concerns bidding strategy, for example ascending/descending auctions. This type of auction is not much represented in the freight transportation markets, however, there are some papers trying to highlight its advantages comparing to the sealed-bid auctions. (Xu and Huang, 2014) explain that the implementation of descending auctions (like Dutch auction) seems to be simpler and more transparent to carriers. Moreover, in descending auctions, carriers are allowed to decrease their bids, so a carrier can start by placing a high bid and revise it when competitors' bids are revealed. While, Cheng et al. (2016) claim that both ascending or descending auctions seem simple enough to be understood by any carrier. The problem may extend to dynamic pricing problem for carriers as studied in (Qiao et al., 2016; 2018).

In freight transportation literature, there are two plausible allocation rules for an auction. Firstprice auctions in which the carrier making the lowest bid claims the item and receives the amount he has bid, and second-price auctions (e.g. Vickrey auction) in which the lowest bid wins the auction, but the winning carrier only receives the amount of the second-lowest bid. Even second-price auctions are proven as truthful bidding mechanism, it is rare in freight transportation literature, contrary to the first-price auctions (Brewer and Plott, 2002; Figliozzi et al., 2007; Kuo and Miller-Hooks, 2012). This could be due to the information privacy issue in real-life application.

Regarding auction period in freight transportation markets, we can distinguish two forms. Single-round auctions involve a one-time submission of bids by carriers, and then the auctioneer would determine the final allocation decisions (Elmaghraby and Keskinocak, 2004). 
While multi-round auctions involve several iterations of submission of bids by carriers and updating allocation decisions by the auctioneer until some stopping criteria are met (Wang and Kopfer, 2014; Li and Zhang, 2015). There is continuing debate over the benefit of having multiple rounds auctions. Kwon et al. (2005) argue that multi-round formats provide information feedback for carriers whereby they can adjust their bids so that better allocations can be made. Ledyard et al. (2002) present their experience of using multi-round combinatorial auctions for Sears Logistics Services. The company has been savings millions of dollars annually by providing rate visibility to carriers based on the received information from previous rounds. Elmaghraby and Keskinocak (2004) describe the experience of Home Depot in using a single round combinatorial auction mechanism for procuring TL transportation service to ship freight to its thousands of stores. Home Depot favored a single round bid in order to reduce the probability of a "damaging price war between carriers" that would result in lower overall service levels.

Besides, all the types of auction mentioned bellow have been studied for both TL and LTL industry. Each type of auction could be studied alone or in combination with other types. Wang and Kopfer (2014) propose a route-based multi-round iterative combinatorial auction for collaborative freight transportation of LTL carriers. Recently, Li and Zhang (2015) study a multi-round auction of carrier collaboration problem in the TL transportation with pickup and delivery requests, by proposing a single request auction mechanism for request exchange.

Negotiation mechanisms are studied in fifteen percent of the articles in the survey. Negotiations appear in a multitude of forms in FTSP. The most traditional one is face-to-face negotiations, and others could include using e-mail, fax, and telephone. Nowadays, several electronic marketplaces propose negotiation mechanisms (Collignon, 2016), wherein shippers post their loads and carriers post their residual capacities. When one party is interested in the other party's offer, one-on-one negotiations start. There are also bilateral and multi-bilateral negotiations (i.e. negotiations between one shipper and several carriers or vice versa). In transportation markets, a negotiation mechanism could be implemented alone or with other mechanisms. Caplice (2007) argues that in any truckload auction there is usually a final soft negotiation round after the WDP is solved. Pontrandolfo et al. (2010) conduct an experiment to compare auction and negotiation mechanisms for TSP. They conclude that the choice of the FTSP mechanism may not be determined solely by the economic performance. The type of mechanism alone has no 
significant effect on the economic outcomes. Nevertheless, the mechanism type could affect the participants' perceptions in evaluating their own outcomes and performance.

Finally, only two percent of the articles in the survey are dealing with catalogs. They are not widely considered in freight transportation research as catalog services and prices are normally pre-defined and static (sometimes negotiable). (Caplice, 2007) explains that catalogs are used by large shippers to manage their TL operations and are replaced by auctions for emergency distraught, or distressed freight.

\subsubsection{Procurement mechanism ownership}

A second observation drawn from Figure 4 is that shipper-owned mechanisms are dominant compared to carrier-owned or third-party-owned mechanisms. The result is consistent with the dominant studies in the literature on reverse auction mechanisms wherein shippers manage the rules (Carter et al., 2004; Carter and Stevens, 2007).

\subsubsection{Transportation mode}

A third observation concerns transportation modes. Figure 4 shows that road transport is dominant compared to other transportation modes (it represents $88 \%$ of transportation modes studied). Indeed, many articles deal with road transportation auction mechanisms. The term bundle is widely used in the literature on combinatorial auction mechanisms for road transportation, whether for FTL or LTL, to estimate the transport synergy between the requests. Among the selected papers, only one (Xu et al., 2015) addresses multimodal transportation.

\subsubsection{Terms of agreement}

According to Table 4 and Figure 4, both long-term procurement plans and short-term practices (spot markets) have been adequately studied, although long-term contract mechanisms have received more attention. Rekik and Mellouli (2012) introduce the concept of reputation-based allocation of lanes for long-term contracts for carriers in truckload transportation procurement auctions. Schwind et al. (2009) propose a long-term combinatorial exchange for medium-sized food delivery industries. Nandiraju and Regan (2005) and Sheffi (2004) claim that in most cases, shippers prefer long- to mid-term transportation service procurement contracts to transport goods to avoid volatility in future prices and to ensure capacity availability and quality of service. However, in some cases, uncertainties (e.g., evolution in shipper's flow or demand, transport market evolution, fuel price fluctuation) may destabilize or disrupt these long- to midterm contracts, forcing shippers to improvise at the last minute and use short-term contracts. 
The latter helps to eliminate some of the complexities of long-term contracts when procurement criteria are clearly defined (Nandiraju and Regan, 2005). Besides, the terms of agreement also depend on the relationships between the actors. Grieger (2003) and Kwon et al. (2009) show that spot markets are more adapted to situations where no close relationship is necessary, while Sharifi et al. (2006) suggest that markets owned by a third-party are more adapted to short-term practices. Various researchers have also addressed the spot market. Figliozzi et al. (2004) introduce a sequential auction format and discusses the truckload procurement in spot markets. Garrido (2007) exploits spot market opportunities by studying the procurement of transportation services with real time information. Mes et al. (2009) develop profit maximization strategies for shippers in the spot market. Xu and Huang (2013) propose a methodology in the spot market to address TSP with asymmetric demand.

\subsubsection{Participants on two sides}

According to Figure 5, many-to-few market (i.e., many shippers-to-few carriers) has received much less attention than others over the last twenty years. Few-to-many market has been obviously the main research stream between 2003-2012. However, research interests have gradually evolved to many-to-many market in the last 5 years. The observation implies that carriers have been in increasing competition over the past years due to the globalization and opening of local markets, so that freight markets are mostly shipper-led. Nevertheless, to avoid the winner-take-all scenario, researchers have been looking for win-win mechanisms in manyto-many market to maximize social welfare.

\subsubsection{Procurement mechanism outcomes}

Many articles focus on individual objective outcomes. For example, references (Ledyard et al., 2002; Alp et al., 2003; Andres Figliozzi et al., 2003; Figliozzi et al., 2005; Lee et al., 2007) state that the use of reverse auctions minimizes (maximizes) the expected total cost (profits) for shippers (carriers), and Kersten (2009) reports that multi-attribute reverse auctions are efficient mechanisms producing efficient solutions that maximize the buyers' utility. Conversely, some articles focus on individual subjective outcomes. Carter and Stevens (2007) study the benefits and drawbacks of using reverse auctions in transportation procurement from different perspectives. On the one hand, some participating suppliers are aware of opportunistic suppliers; on the other hand, from the buyer's perspective, reverse auctions can yield lower purchase prices. Moreover, Gattiker et al. (2007) underline that sellers who use negotiation always report greater trust in their buyer counterparts than sellers using reverse auctions. Finally, there are also some articles that focus on market outcomes and propose efficient 
resource allocation mechanisms that minimize the total transportation cost, see (Xu and Huang, 2013; 2014; $\mathrm{Xu}$ et al., 2015). Figure 4 shows that any subjective outcomes are given less importance and less attention compared to objective outcomes and market outcomes.

\subsubsection{Article research methodology}

Figure 4 shows that computational and numerical experiments are by far the most common in the literature. Most of the studies attempt to use mathematical models or simulation techniques. Berger and Bierwirth (2010) propose a mathematical model for collaborative carrier networks wherein carriers exchange lanes in order to maximize the total profit without decreasing the individual profit. Guo et al. (2006) develop a mathematical model for the carrier assignment problem (CAP). Lee et al. (2007) develop a nonlinear integer programming model for the bid generation problem (BGP) to maximize the profit. Ma et al. (2010) formulate a two-stage integer programming model for CAP. Chang (2009) develops a bidding advisor for solving the bids generation problem for carriers by using a heuristic procedure. Figliozzi et al. (2006) use a simulation framework to evaluate different strategies adopted in sequential auctions for TSP. Ağralı et al. (2008) use a simulation study to evaluate the performance of the spot market. Zhang et al. (2014) use a Monte Carlo Approximation method to solve a two-stage stochastic WDP under volume uncertainty. Mes et al. (2009) conduct a simulation study to analyze the performance of the dynamic threshold policy adopted by the shipper in the spot market. Song and Regan (2005) conduct an experiment based on simulation experiment to examine the performance of the proposed bid construction method involved in BGP. Moreover, multi-agent systems could be used as an important tool in FTSP. Robu et al. (2011) shed light on the effectiveness of agent-based systems in day-to-day transportation outsourcing activities.

Fifteen percent of the articles studied in the literature review operate case studies. Ağralı et al. (2008) consider the logistics spot market in Turkey to evaluate its performance. Hedvall et al. (2017) consider three case studies to explore the variety in FTSP approaches and the impact of these on vehicle utilization.

Eight percent of the articles studied in the literature review comprise conceptual studies that report issues and challenges in FTSP without any simulation or mathematical models. Caplice and Sheffi (2003) discuss FTSP as a whole by giving a detailed review of important issues related to combinatorial auctions. Sheffi (2004) studies the benefits of combinatorial auctions in FTSP. 
Surprisingly, few researchers carry out empirical evaluations. Kuyzu et al. (2015) empirically evaluate the value of bid price optimization for carriers simulating a real-life environment. Song and Regan (2003) suggests «co-opetition » as a strategy option, which is a combination of competition and cooperation between ports, and explains empirically the case of co-opetition between container ports in South China and Hong Kong. (Marin and Sicotte, 2003) show through an empirical study that contracts increase carriers' profits and market power. Only $10 \%$ of the articles studied in the literature review comprise empirical evaluations.

\subsection{Research trends and Gaps}

This section aims to reveal evolutionary trends in the research on FTSP, and to determine the areas where research gaps are evident, in order to outline the future research perspectives.

Our first remark from the survey is that the application of mechanism design theory has become a popular approach to design auction mechanisms for FTSP. According to the theory, there are four principles as the main goals for an auction mechanism, that are incentive compatible (IC), allocatively efficient (AE), individual rationality (IR), and budget balance (BB), see Klemperer (1999) for the definitions. Huang and Xu (2013) are among the first studies that propose three truthful multi-unit trade auction mechanisms in freight transportation that ensure IC, IR, BB, and AE. Further studies would be of great interest in this field.

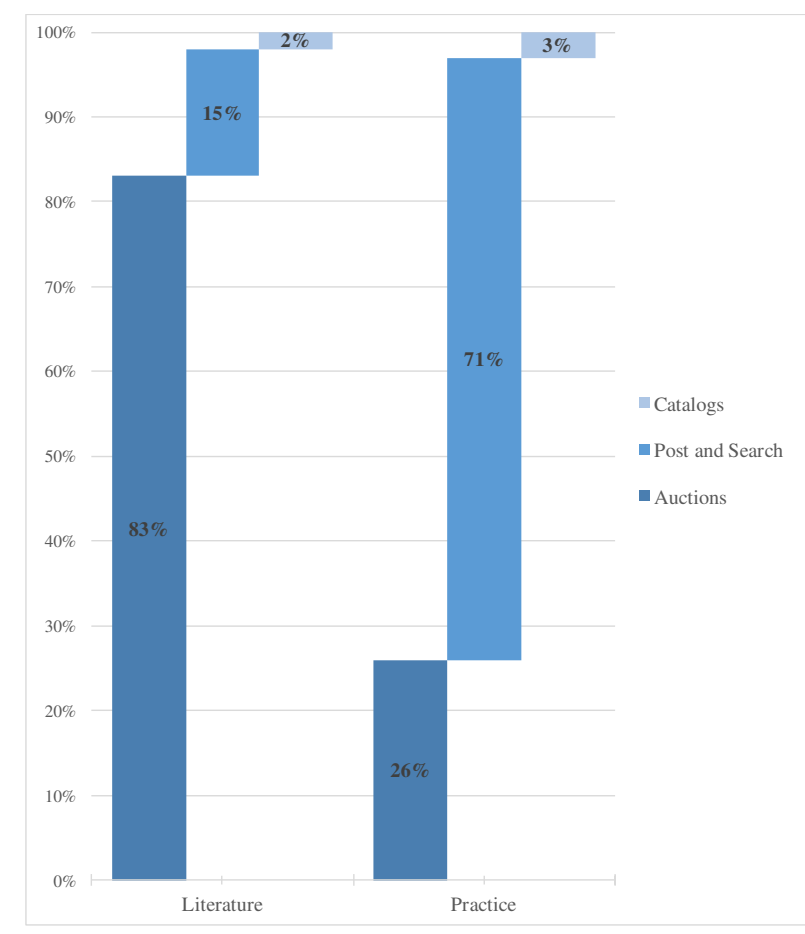

Figure 7. Mechanisms studied in the literature and in practice (based on Collignon (2016)) 
Secondly, very few papers in the survey have studied the applications of FTSP mechanisms in practice. Some contradictory findings have been revealed with regards the types of mechanisms studied in literature comparing to those existing in practice as shown in Figure 7. In practice, the most popular mechanism is negotiation which is way ahead of auctions (see Collignon (2016)); however, auctions are the most addressed mechanisms in literature. Additional studies should be done in this direction, to explain the reasons of this gap. One of the reasons for this difference could be the link between mechanism and fee structure. Mechanisms relying on intermediaries would generate additional fees (e.g., commissions of the intermediary). Another reason could also be the added complexity of implementing auction mechanisms since a market broker is usually present at the auctions. Moreover, the complexity of procurement could also influence seller trust.

Thirdly, research interests have gradually expanded to third-party-owned mechanisms, especially over the last five years, as depicted in Figure 5. Early studies (1998-2007) were limited to reverse auction mechanisms managed by shippers. However, studies in recent years have focused more on mechanisms based on trust and sharing responsibilities between all the trading parties to achieve effectiveness and efficiency. As mentioned above, research is trending toward assessing cooperative or collaborative transportation systems that require new mechanisms managed by a third-party to avoid shipper/carrier opportunism and loss of trust between shippers and carriers.

Fourthly, mechanism for multimodal transportation deserves more attention. Numerous studies have focused on auction-based single-mode transportation while little attention has been paid to auction-based multimodal transportation (Crainic and Kim, 2007; Caris et al., 2013; SteadieSeifi et al., 2014). Further studies would be necessary due to the increasing importance of multimodal transportation.

Fifthly, in recent years, the emergence of new online decentralized freight marketplaces (for short-term services in particular) has led to the need to study many-to-many markets. Moreover, with the emergence of horizontal collaborative transportation systems, it is necessary to study many carriers-to-few shippers markets that require cooperation between carriers as well as new procurement mechanisms. 
Sixthly, regarding outcomes, the literature addressing collaboration issues as a new way of procuring transportation services needs to focus more on non-financial outcomes such as ontime performance and pick-up performance in order to maintain the collaboration. It also needs researchers to focus more on the question of who will organize the auction mechanism, the shipper or the carrier.

Finally, concerning research methodology, the emergence of new markets and organizational models will need empirical research to study how a change in the actors' structures will affect their behavior. Empirical studies are necessary to estimate the effectiveness, the efficiency, and the usability of a procurement mechanism in a transport market.

\section{New Opportunities and Challenges in E-commerce}

As discussed in Section 2, the need for innovations for transportation organizations and FTSP mechanisms corresponds to that of the new omnichannel and $\mathrm{O} 2 \mathrm{O}$ E-commerce business environment in which the flows are characterized as small with fluctuating volumes and short lead times. Based on the results reported from the survey above, this section identifies some promising research lines and prospects, that deserve further attention and develops a research agenda for FTSP in E-commerce.

\subsection{Mechanisms for on-demand transportation in E-commerce}

On-demand transport requests have been thoroughly investigated for passenger transportation (e.g., taxis) but not for freight transportation (Egan and Jakob, 2016). However, it has become an important trend in E-commerce and last mile delivery in particular. Like Amazon Prime Now, more and more e-tailers are proposing same-day delivery. Short lead times and narrow time windows make it very difficult to consolidate deliveries and optimize the transport plan for all of them. Consequently, in most cases, each order is delivered independently thus rendering the transportation unsustainable. Some innovative solutions have been studied to deal with the issue, for example, dynamic vehicle routing, transport autonomy (e.g., AGV, drone), or crowdsourced delivery services (e.g., Uber, Deliveroo, Stuart). Currently, a popular procurement mechanism for on-demand services is that the shipper (or client) pays a known price via a platform for each on-demand service, i.e., spot markets with service catalogue. The major drawback is that resource utilization efficiency and trading effectiveness are not optimized by such mechanisms, despite the use of surge pricing proposed by some platforms such as Uber. As proven by the literature, double auctions could be more efficient and effective 
in such contexts (Xu and Huang, 2017). However, it is important to understand why the mechanism is still rarely applied in real practice, and how it can be put into practice.

\subsection{Mechanisms for sharing economies}

The rise of sharing economies in freight transportation requires also innovations on procurement mechanisms. Savelsbergh and Van Woensel (2016) define two models of sharing economies. The first is collaborative consumption in Consumer to Consumer (C2C) networks, for example crowdsourcing shipping, or freight and people ride sharing. The second is collaborative business in Business to Business (B2B) networks, that could be horizontal cooperation or interconnection of logistics services (Pan et al., 2019). Both could be applied in logistics services, including national and city-wide transportation that are crucial to Ecommerce. But the procurement mechanism could be different, and impacts differently the feasibility and performance of the solution. For example, in collaborative consumption, third party organizer (like Uber) would prefer using catalogue with surge pricing rather than auction mechanisms, to avoid price competition and instability. In collaborative business, collaborating companies would prefer adapting gain sharing mechanism rather than procurement for each occasional sharing. As sharing economies would become more and more important in logistics and freight transport, it is worth further investigating the appropriateness of the exiting mechanisms for different collaboration and sharing models, or develop new ones.

\subsection{Intermodality and synchromodality for E-commerce}

Recent challenges in omnichannel or $\mathrm{O} 2 \mathrm{O}$ E-commerce transportation reveal the great potential of intermodal and synchromodal transportation. This is particularly important for global Ecommerce (Xu et al., 2015), as the end-to-end supply chain includes cross-board, national, and city-wide transportation. Some logistics planning services (LPS) provide global logistics services but how to synchronize and optimize the transportation services involved is still an issue, especially with regards to cost-efficiency and sustainability. Synchromodal freight transportation is a recent concept to this end. It is a network of interconnected, wellsynchronized transport modes that, together, cater dynamically for the demands and instantaneous needs of shippers (Ambra et al., 2018). To achieve win-win situations in synchromodal business, cooperation among players is essential, and there is a need to introduce new mechanisms that ensure risk sharing and trust between actors that may feel reluctant to cooperate with each other for fear of competition. Mechanisms managed by a third-party are needed to avoid shipper/carrier opportunism and loss of trust between actors. Moreover, new 
mechanisms have to be introduced to assess actor preferences and support the flexibility and reliability of synchromodal systems. Synchronized transport systems have even evolved into decentralized, highly distributed systems (e.g., Physical Internet) to improve interoperability between transportation modes, optimize capacity utilization and tailor services to the needs of shippers (Montreuil, 2011). This concept, resulting in collaborative, highly distributed and leveraged logistics needs new procurement mechanisms to handle the flexible door-to-door arrangements between the different actors.

\subsection{Procurement mechanism for sustainable city logistics}

It is foreseeable that procurement mechanisms should take sustainability into account as it is becoming a major constraint in transportation, especially with regards to city logistics. However, until now only a few studies have investigated the problem (Jothi Basu et al., 2015; Jothi Basu et al., 2017). These studies question how to integrate sustainability criteria (e.g., transport emissions) into procurement mechanisms and decisions. For example, using auction mechanisms to assign carriers while considering emissions saved through the auction (Jothi Basu et al., 2015). Furthermore, it is important to study the efficiency and effectiveness of the well-known mechanisms (i.e., auction, catalog, negotiation) for sustainability purposes. These studies are still lacking in the literature.

\section{Conclusion}

Based on a review of the literature, this paper investigates the existing freight transportation organization and procurement mechanisms, and discusses their challenges and opportunities in the context of omnichannel and $\mathrm{O} 2 \mathrm{O}$ E-commerce. A systematic review framework was developed and a total of 78 journal articles were reviewed and analyzed. Some essential findings offer a way to better understand the strengths and limits of the existing freight transportation service procurement mechanisms. Based on quantitative and qualitative analyses and the comparison between research and real-world practices, this study identifies some research topics that deserve further attention for E-commerce transportation in particular. The goal of this literature review was not necessarily to find a particular mechanism for a specific case but to provide a clear review to help improve understanding of procurement mechanisms and to guide practitioners and researchers in this field. In addition, as this literature review focused on the application of mechanisms in the field of logistics and freight transportation, some studies in other fields (e.g., computer science, economics) were excluded. This can be considered as a limitation of this work. 


\section{References}

Abdulkadiroğlu, A., Sönmez, T., 2003. School choice: A mechanism design approach. American economic review. 93 (3), 729-747.

Agatz, N. A. H., Fleischmann, M., van Nunen, J. A. E. E., 2008. E-fulfillment and multichannel distribution - A review. European Journal of Operational Research. 187 (2), 339-356. https://doi.org/10.1016/j.ejor.2007.04.024

Ağralı, S., Tan, B., Karaesmen, F., 2008. Modeling and analysis of an auction-based logistics market. European Journal of Operational Research. 191 (1), 272-294. http://doi.org/10.1016/j.ejor.2007.08.018

Alp, O., Erkip, N. K., Güllü, R., 2003. Outsourcing Logistics: Designing Transportation Contracts Between a Manufacturer and a Transporter. Transportation Science. 37 (1), 23-39. https://doi.org/10.1287/trsc.37.1.23.12818

Ambra, T., Caris, A., Macharis, C., 2018. Towards freight transport system unification: reviewing and combining the advancements in the physical internet and synchromodal transport research. International Journal of Production Research. 1-18 (in press). https://doi.org/10.1080/00207543.2018.1494392

Andres Figliozzi, M., Mahmassani, H., Jaillet, P., 2003. Framework for study of carrier strategies in auction-based transportation marketplace. Transportation Research Record: Journal of the Transportation Research Board. (1854), 162-170. https://doi.org/10.3141/185418

Archetti, C., Savelsbergh, M., Speranza, M. G., 2016. The vehicle routing problem with occasional drivers. European Journal of Operational Research. 254 (2), 472-480.

Balasubramanian, S., 1998. Mail versus Mall: A Strategic Analysis of Competition between Direct Marketers and Conventional Retailers. Marketing Science. 17 (3), 181-195. https://doi.org/10.1287/mksc.17.3.181

Berger, S., Bierwirth, C., 2010. Solutions to the request reassignment problem in collaborative carrier networks. Transportation Research Part E: Logistics and Transportation Review. 46 (5), 627-638. http://dx.doi.org/10.1016/j.tre.2009.12.006

Brewer, P. J., Plott, C. R., 2002. A Decentralized, Smart Market Solution to a Class of BackHaul Transportation Problems: Concept and Experimental Test Beds. Interfaces. 32 (5), 13-36. https://doi.org/10.1287/inte.32.5.13.27

Buer, T., Kopfer, H., 2014. A Pareto-metaheuristic for a bi-objective winner determination problem in a combinatorial reverse auction. Computers \& Operations Research. 41, 208-220. http://doi.org/10.1016/j.cor.2013.04.004

Buer, T., Pankratz, G., 2010. Solving a bi-objective winner determination problem in a transportation procurement auction. Logistics Research. 2 (2), 65-78. https://doi.org/10.1007/s12159-010-0031-8

Caplice, C., 2007. Electronic Markets for Truckload Transportation. Production and Operations Management. 16 (4), 423-436. https://doi.org/10.1111/j.1937-5956.2007.tb00270.x

Caplice, C., Sheffi, Y., 2003. Optimization - based procurement for transportation services. Journal of Business Logistics. 24 (2), 109-128. https://doi.org/10.1002/j.21581592.2003.tb00048.x

Caris, A., Macharis, C., Janssens, G. K., 2013. Decision support in intermodal transport: A new research agenda. Computers in Industry. 64 (2), 105-112. https://doi.org/10.1016/j.compind.2012.12.001

Carter, C. R., Kaufmann, L., Beall, S., Carter, P. L., Hendrick, T. E., Petersen, K. J., 2004. Reverse auctions-grounded theory from the buyer and supplier perspective. Transportation Research Part E: Logistics and Transportation Review. 40 (3), 229-254. http://doi.org/10.1016/j.tre.2003.08.004 
Carter, C. R., Stevens, C. K., 2007. Electronic reverse auction configuration and its impact on buyer price and supplier perceptions of opportunism: A laboratory experiment. Journal of Operations Management. 25 (5), 1035-1054. http://doi.org/10.1016/j.jom.2006.10.005

Chang, T.-S., 2009. Decision support for truckload carriers in one-shot combinatorial auctions. Transportation Research Part B: Methodological. 43 (5), 522-541. http://doi.org/10.1016/j.trb.2008.09.003

Chen, C., Pan, S., Wang, Z., Zhong, R. Y., 2017. Using taxis to collect citywide E-commerce reverse flows: a crowdsourcing solution. International Journal of Production Research. 55 (7), 1833-1844. https://doi.org/10.1080/00207543.2016.1173258

Chen, H., 2016. Combinatorial clock-proxy exchange for carrier collaboration in less than truck load transportation. Transportation Research Part E: Logistics and Transportation Review. 91, 152-172. http://dx.doi.org/10.1016/j.tre.2016.04.008

Chen, R. L.-Y., AhmadBeygi, S., Cohn, A., Beil, D. R., Sinha, A., 2009. Solving Truckload Procurement Auctions Over an Exponential Number of Bundles. Transportation Science. 43 (4), 493-510. https://doi.org/10.1287/trsc.1090.0273

Cheng, C.-B., 2011. Reverse auction with buyer-supplier negotiation using bi-level distributed programming. European Journal of Operational Research. 211 (3), 601-611. http://doi.org/10.1016/j.ejor.2011.01.017

Cheng, M., Xu, S. X., Huang, G. Q., 2016. Truthful multi-unit multi-attribute double auctions for perishable supply chain trading. Transportation Research Part E: Logistics and Transportation Review. 93, 21-37. http://dx.doi.org/10.1016/j.tre.2016.05.009

Collignon, S. E., 2016. Exploratory and Empirical Analysis of E-Marketplaces for Truck Transportation Services Procurement.

Crainic, T. G., Kim, K. H. (2007). Chapter 8 Intermodal Transportation. Handbooks in Operations Research and Management Science. C. Barnhart and G. Laporte, Elsevier. 14: 467537.

Dahl, S., Derigs, U., 2011. Cooperative planning in express carrier networks - An empirical study on the effectiveness of a real-time Decision Support System. Decision Support Systems. 51 (3), 620-626. http://doi.org/10.1016/j.dss.2011.02.018

Durach, C. F., Kembro, J., Wieland, A., 2017. A new paradigm for systematic literature reviews in supply chain management. Journal of Supply Chain Management. 53 (4), 67-85. https://doi.org/10.1111/jscm.12145

Egan, M., Jakob, M., 2016. Market mechanism design for profitable on-demand transport services. Transportation Research Part B: Methodological. 89, 178-195. http://dx.doi.org/10.1016/j.trb.2016.04.020

Elmaghraby, W., Keskinocak, P. (2004). Combinatorial auctions in procurement. The practice of supply chain management: Where theory and application converge. Springer: 245-258.

Eurostat (2017). Road freight transport by journey characteristics. Europe.

Figliozzi, M., Mahmassani, H., Jaillet, P., 2004. Competitive performance assessment of dynamic vehicle routing technologies using sequential auctions. Transportation Research Record: Journal of the Transportation Research Board. (1882), 10-18. https://doi.org/10.3141/1882-02

Figliozzi, M., Mahmassani, H., Jaillet, P., 2005. Impacts of auction settings on the performance of truckload transportation marketplaces. Transportation Research Record: Journal of the Transportation Research Board. (1906), 89-96. https://doi.org/10.3141/1906-11

Figliozzi, M., Mahmassani, H., Jaillet, P., 2006. Quantifying opportunity costs in sequential transportation auctions for truckload acquisition. Transportation Research Record: Journal of the Transportation Research Board. (1964), 247-252. https://doi.org/10.3141/1964-27

Figliozzi, M. A., Mahmassani, H. S., Jaillet, P., 2007. Pricing in Dynamic Vehicle Routing Problems. Transportation Science. 41 (3), 302-318. https://doi.org/10.1287/trsc.1070.0193 
Gansterer, M., Hartl, R. F., 2016. Request evaluation strategies for carriers in auction-based collaborations. OR Spectrum. 38 (1), 3-23. https://doi.org/10.1007/s00291-015-0411-1

Garrido, R. A., 2007. Procurement of transportation services in spot markets under a doubleauction scheme with elastic demand. Transportation Research Part B: Methodological. 41 (9), 1067-1078. http://doi.org/10.1016/j.trb.2007.04.001

Gattiker, T. F., Huang, X., Schwarz, J. L., 2007. Negotiation, email, and Internet reverse auctions: How sourcing mechanisms deployed by buyers affect suppliers' trust. Journal of Operations Management. 25 (1), 184-202. http://doi.org/10.1016/j.jom.2006.02.007

Goldsby, T. J., Eckert, J. A., 2003. Electronic transportation marketplaces: a transaction cost perspective. Industrial Marketing Management. $32 \quad$ (3), 187-198. http://dx.doi.org/10.1016/S0019-8501(02)00262-6

Grieger, M., 2003. Electronic marketplaces: A literature review and a call for supply chain management research. European journal of operational research. 144 (2), 280-294. https://doi.org/10.1016/S0377-2217(02)00394-6

Guo, Y., Lim, A., Rodrigues, B., Zhu, Y., 2006. Carrier assignment models in transportation procurement. Journal of the Operational Research Society. 57 (12), 1472-1481. https://doi.org/10.1057/palgrave.jors.2602131

Handoko, S. D., Lau, H. C., 2016. Enabling Carrier Collaboration via Order Sharing Double Auction: A Singapore Urban Logistics Perspective. Transportation Research Procedia. 12, 777 786. http://dx.doi.org/10.1016/j.trpro.2016.02.031

Hedvall, K., Dubois, A., Lind, F., 2017. Variety in freight transport service procurement $\begin{array}{llll}\text { approaches. } & \text { Transportation } & \text { research } & \text { 806-823. }\end{array}$ https://doi.org/10.1016/j.trpro.2017.05.459

Hu, Q., Zhang, Z., Lim, A., 2016. Transportation service procurement problem with transit time.

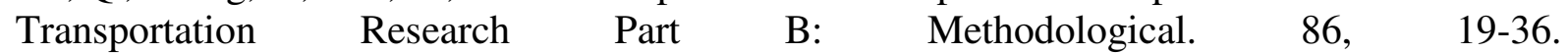
http://doi.org/10.1016/j.trb.2016.01.007

Huang, G. Q., Xu, S. X., 2013. Truthful multi-unit transportation procurement auctions for logistics e-marketplaces. Transportation Research Part B: Methodological. 47, 127-148. http://doi.org/10.1016/j.trb.2012.10.002

Hübner, A., Kuhn, H., Wollenburg, J., 2016a. Last mile fulfilment and distribution in omnichannel grocery retailing: A strategic planning framework. International Journal of Retail \& Distribution Management. 44 (3), 228-247. https://doi.org/10.1108/IJRDM-11-2014-0154

Hübner, A., Wollenburg, J., Holzapfel, A., 2016b. Retail logistics in the transition from multichannel to omni-channel. International Journal of Physical Distribution \& Logistics Management. 46 (6/7), 562-583. https://doi.org/10.1108/IJPDLM-08-2015-0179

International Energy Agency (2017). CO2 emissions from fuel combustion. Statistics, OECD/IEA, Paris.

Jothi Basu, R., Bai, R., Palaniappan, P. K., 2015. A strategic approach to improve sustainability in transportation service procurement. Transportation Research Part E: Logistics and Transportation Review. 74, 152-168. http://dx.doi.org/10.1016/j.tre.2014.10.015

Jothi Basu, R., Subramanian, N., Cheikhrouhou, N., 2015. Review of full truckload transportation service procurement. Transport Reviews. 35 (5), 599-621. https://doi.org/10.1080/01441647.2015.1038741

Jothi Basu, R., Subramanian, N., Gunasekaran, A., Palaniappan, P. L. K., 2017. Influence of non-price and environmental sustainability factors on truckload procurement process. Annals of Operations Research. 250 (2), 363-388. https://doi.org/10.1007/s10479-016-2170-z

Kersten, G. E., 2009. Multiattribute Procurement Auctions: Efficiency and Social Welfare in Theory and Practice. Decision Analysis. 11 (4), 215-232. https://doi.org/10.1287/deca.2014.0299 
Klemperer, P., 1999. Auction theory: A guide to the literature. Journal of economic surveys. 13 (3), 227-286. https://doi.org/10.1111/1467-6419.00083

Koufteros, X., Mackleprang, A., Hazen, B. T., Huo, B., 2018. Structured literature reviews on strategic issues in SCM and logistics part 1. International Journal of Physical Distribution \& Logistics Management. 48 (3), 202-204. https://doi.org/10.1108/IJPDLM-04-2018-360

Kuo, A., Miller-Hooks, E., 2012. Developing Responsive Rail Services through collaboration. Transportation Research Part B: Methodological. 46 (3), 424-439. http://dx.doi.org/10.1016/j.trb.2011.10.009

Kuo, A., Miller-Hooks, E., 2015. Combinatorial auctions of railway track capacity in vertically separated freight transport markets. Journal of Rail Transport Planning \& Management. 5 (1), 1-11. http://dx.doi.org/10.1016/j.jrtpm.2014.12.001

Kuyzu, G., 2017. Lane covering with partner bounds in collaborative truckload transportation

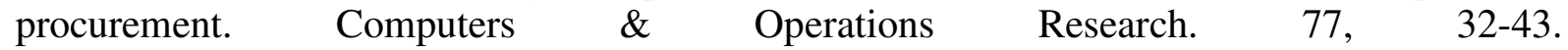
https://doi.org/10.1016/j.cor.2016.07.018

Kuyzu, G., Akyol, Ç. G., Ergun, Ö., Savelsbergh, M., 2015. Bid price optimization for truckload carriers in simultaneous transportation procurement auctions. Transportation Research Part B: Methodological. 73, 34-58. http://dx.doi.org/10.1016/j.trb.2014.11.012

Kwon, R. H., Lee, C.-G., Ma, Z., 2005. An integrated combinatorial auction mechanism for truckload transportation procurement. University of Toronto, Working Paper.

Kwon, S., Yoo, B., Kim, J., Shang, W., Lee, G., 2009. Reservation price reporting mechanisms for online negotiations. Decision Support Systems. 46 (4), 755-762. https://doi.org/10.1016/j.dss.2008.11.006

Lalive, R., Luechinger, S., Schmutzler, A., 2017. Does expanding regional train service reduce air pollution? Journal of Environmental Economics and Management. 1-21 (in press). https://doi.org/10.1016/j.jeem.2017.09.003

Ledyard, J. O., Olson, M., Porter, D., Swanson, J. A., Torma, D. P., 2002. The First Use of a Combined-Value Auction for Transportation Services. Interfaces. 32 (5), 4-12. https://doi.org/10.1287/inte.32.5.4.30

Lee, C.-G., Kwon, R. H., Ma, Z., 2007. A carrier's optimal bid generation problem in combinatorial auctions for transportation procurement. Transportation Research Part E: Logistics and Transportation Review. 43 (2), 173-191. http://dx.doi.org/10.1016/j.tre.2005.01.004

Li, L., Zhang, R. Q., 2015. Cooperation through capacity sharing between competing forwarders. Transportation Research Part E: Logistics and Transportation Review. 75, 115-131. http://dx.doi.org/10.1016/j.tre.2014.11.003

Li, Y., Chen, H., Prins, C., 2016. Adaptive large neighborhood search for the pickup and delivery problem with time windows, profits, and reserved requests. European Journal of Operational Research. 252 (1), 27-38. https://doi.org/10.1016/j.ejor.2015.12.032

Lim, A., Qin, H., Xu, Z., 2012. The freight allocation problem with lane cost balancing constraint. European Journal of Operational Research. 217 (1), 26-35. http://dx.doi.org/10.1016/j.ejor.2011.08.028

Lim, A., Rodrigues, B., Xu, Z., 2008. Transportation Procurement with Seasonally Varying Shipper Demand and Volume Guarantees. Operations Research. 56 (3), 758-771. https://doi.org/10.1287/opre.1070.0481

Lindsey, C., Mahmassani, H. S., 2017. Sourcing truckload capacity in the transportation spot market: A framework for third party providers. Transportation Research Part A: Policy and Practice. 102, 261-273. https://doi.org/10.1016/j.tra.2016.10.001

Ma, Z., Kwon, R. H., Lee, C.-G., 2010. A stochastic programming winner determination model for truckload procurement under shipment uncertainty. Transportation Research Part E: Logistics and Transportation Review. 46 (1), 49-60. http://dx.doi.org/10.1016/j.tre.2009.02.002 
Marin, P. L., Sicotte, R., 2003. Exclusive contracts and market power: evidence from ocean shipping. The Journal of Industrial Economics. 51 (2), 193-214. https://doi.org/10.1111/14676451.00198

Mes, M., van der Heijden, M., Schuur, P., 2009. Dynamic threshold policy for delaying and breaking commitments in transportation auctions. Transportation Research Part C: Emerging Technologies. 17 (2), 208-223. http://doi.org/10.1016/j.trc.2008.03.001

Mesa-Arango, R., Ukkusuri, S. V., 2013. Benefits of in-vehicle consolidation in less than truckload freight transportation operations. Transportation Research Part E: Logistics and Transportation Review. 60, 113-125. http://dx.doi.org/10.1016/j.tre.2013.05.007

Montreuil, B., 2011. Toward a Physical Internet: meeting the global logistics sustainability grand challenge. Logistics Research. 3 (2-3), 71-87. https://doi.org/10.1007/s12159-011-0045$\mathrm{X}$

Nandiraju, S., Regan, A. (2005). Freight transportation electronic marketplaces: A survey of market clearing mechanisms and exploration of important research issues. Proceedings 84th Annual Meeting of the Transportation Research Board, Washington DC, Citeseer.

Nisan, N., 2007. Introduction to mechanism design (for computer scientists). Algorithmic game theory. 9, 209-242.

Özener, O. Ö., Ergun, Ö., Savelsbergh, M., 2011. Lane-Exchange Mechanisms for Truckload

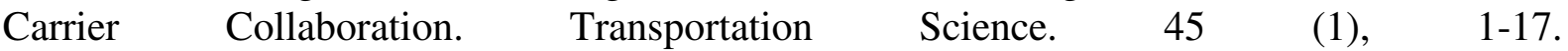
https://doi.org/10.1287/trsc. 1100.0327

Pan, S., Trentesaux, D., Ballot, E., Huang, G. Q., 2019. Horizontal Collaborative Transport: survey of solutions and practical implementation issues. International Journal of Production Research (in press). https://doi.org/10.1080/00207543.2019.1574040

Pan, S., Trentesaux, D., Ballot, E., Huang, G. Q., 2019. Horizontal collaborative transport: survey of solutions and practical implementation issues AU - Pan, Shenle. International Journal of Production Research. 1-22. https://doi.org/10.1080/00207543.2019.1574040

Park, S., Rothkopf, M. H., 2005. Auctions with bidder-determined allowable combinations. European Journal of Operational Research. 161 (2), 399-415. https://doi.org/10.1016/j.ejor.2003.08.057

Parsons, S., Rodriguez-Aguilar, J. A., Klein, M., 2011. Auctions and bidding: A guide for computer scientists. ACM Computing Surveys (CSUR). 43 (2), 10.

Paul, J., Agatz, N., Spliet, R., De Koster, R., 2019. Shared Capacity Routing Problem- An omni-channel retail study. European Journal of Operational Research. 273 (2), 731-739. https://doi.org/10.1016/j.ejor.2018.08.027

Pontrandolfo, P., Wu, S., Moramarco, R., Kersten, G. (2010). Auctions and negotiations in transportation service procurement. Proceedings of group decision and negotiations conference. Qiao, B., Pan, S., Ballot, E., 2016. Dynamic pricing model for less-than-truckload carriers in the Physical Internet. Journal of Intelligent Manufacturing. 1-13 (in press). https://doi.org/10.1007/s10845-016-1289-8

Qiao, B., Pan, S., Ballot, E., 2018. Revenue optimization for less-than-truckload carriers in the Physical Internet: dynamic pricing and request selection. Computers \& Industrial Engineering. https://doi.org/10.1016/j.cie.2018.12.010

Qin, H., Luo, M. F., Gao, X., Lim, A., 2012. The freight allocation problem with all-units quantity-based discount: A heuristic algorithm. Omega-International Journal of Management Science. 40 (4), 415-423. https://doi.org/10.1016/j.omega.2011.05.005

Rekik, M., Mellouli, S., 2012. Reputation-based winner determination problem for combinatorial transportation procurement auctions. Journal of the Operational Research Society. 63 (10), 1400-1409. https://doi.org/10.1057/jors.2011.108 
Remli, N., Rekik, M., 2013. A robust winner determination problem for combinatorial transportation auctions under uncertain shipment volumes. Transportation Research Part C: Emerging Technologies. 35, 204-217. http://doi.org/10.1016/j.trc.2013.07.006

Robu, V., Noot, H., La Poutré, H., van Schijndel, W.-J., 2011. A multi-agent platform for auction-based allocation of loads in transportation logistics. Expert Systems with Applications. 38 (4), 3483-3491. http://doi.org/10.1016/j.eswa.2010.08.136

Sandholm, T., Levine, D., Concordia, M., Martyn, P., Hughes, R., Jacobs, J., Begg, D., 2006. Changing the game in strategic sourcing at Procter \& Gamble: Expressive competition enabled by optimization. Interfaces. 36 (1), 55-68. https://doi.org/10.1287/inte.1050.0185

Savelsbergh, M., Van Woensel, T., 2016. 50th anniversary invited article-city logistics: Challenges and opportunities. Transportation Science. 50 (2), 579-590.

Schwind, M., Gujo, O., Vykoukal, J., 2009. A combinatorial intra-enterprise exchange for logistics services. Information Systems and e-Business Management. 7 (4), 447-471. https://doi.org/10.1007/s10257-008-0102-4

Sharifi, H., Kehoe, D. F., Hopkins, J., 2006. A classification and selection model of emarketplaces for better alignment of supply chains. Journal of Enterprise Information Management. 19 (5), 483-503. https://doi.org/10.1108/17410390610703639

Sheffi, Y., 2004. Combinatorial Auctions in the Procurement of Transportation Services. Interfaces. 34 (4), 245-252. https://doi.org/10.1287/inte.1040.0075

Song, J., Regan, A., 2003. Combinatorial auctions for transportation service procurement: The carrier perspective. Transportation Research Record: Journal of the Transportation Research Board. (1833), 40-46. https://doi.org/10.3141/1833-06

Song, J., Regan, A., 2005. Approximation algorithms for the bid construction problem in combinatorial auctions for the procurement of freight transportation contracts. Transportation Research Part B: Methodological. 39 (10), 914-933. http://doi.org/10.1016/j.trb.2004.11.003

SteadieSeifi, M., Dellaert, N. P., Nuijten, W., Van Woensel, T., Raoufi, R., 2014. Multimodal freight transportation planning: A literature review. European Journal of Operational Research. 233 (1), 1-15. https://doi.org/10.1016/j.ejor.2013.06.055

Touboulic, A., Walker, H., 2015. Theories in sustainable supply chain management: a structured literature review. International Journal of Physical Distribution \& Logistics Management. 45 (1/2), 16-42. https://doi.org/10.1108/IJPDLM-05-2013-0106

Triki, C., Mirmohammadsadeghi, S., Piya, S., 2017. Heuristic methods for the periodic Shipper Lane Selection Problem in transportation auctions. Computers \& Industrial Engineering. 106, 182-191. http://doi.org/10.1016/j.cie.2017.02.005

Triki, C., Oprea, S., Beraldi, P., Crainic, T. G., 2014. The stochastic bid generation problem in combinatorial transportation auctions. European Journal of Operational Research. 236 (3), 991999. https://doi.org/10.1016/j.ejor.2013.06.013

van Duin, J. H. R., Tavasszy, L. A., Taniguchi, E., 2007. Real time simulation of auctioning and re-scheduling processes in hybrid freight markets. Transportation Research Part B: Methodological. 41 (9), 1050-1066. http://dx.doi.org/10.1016/j.trb.2007.04.007

Verhoef, P. C., Kannan, P. K., Inman, J. J., 2015. From multi-channel retailing to omni-channel retailing: introduction to the special issue on multi-channel retailing. Journal of retailing. 91 (2), 174-181. https://doi.org/10.1016/j.jretai.2015.02.005

Wang, D., Wang, N., 2015. Quantum computation based bundling optimization for combinatorial auction in freight service procurements. Computers \& Industrial Engineering. 89, 186-193. http://doi.org/10.1016/j.cie.2014.11.014

Wang, S., Archer, N. P., 2007. Electronic marketplace definition and classification: literature review and clarifications. Enterprise Information Systems. 1 (1), 89-112. https://doi.org/10.1080/17517570601088380 
Wang, X., Kopfer, H., 2014. Collaborative transportation planning of less-than-truckload freight. OR Spectrum. 36 (2), 357-380. https://doi.org/10.1007/s00291-013-0331-x

Wang, X., Xia, M., 2005. Combinatorial bid generation problem for transportation service procurement. Transportation Research Record: Journal of the Transportation Research Board. (1923), 189-198. https://doi.org/10.3141/1923-20

Wang, Y., Zhang, D., Liu, Q., Shen, F., Lee, L. H., 2016. Towards enhancing the last-mile delivery: An effective crowd-tasking model with scalable solutions. Transportation Research Part E: Logistics and Transportation Review. 93, 279-293. https://doi.org/10.1016/j.tre.2016.06.002

Wee, B. V., Banister, D., 2016. How to write a literature review paper? Transport Reviews. 36 (2), 278-288. https://doi.org/10.1080/01441647.2015.1065456

Xu, S. X., Cheng, M., Huang, G. Q., 2015. Efficient intermodal transportation auctions for B2B e-commerce logistics with transaction costs. Transportation Research Part B: Methodological. 80, 322-337. http://doi.org/10.1016/j.trb.2015.07.022

Xu, S. X., Huang, G. Q., 2013. Transportation service procurement in periodic sealed double auctions with stochastic demand and supply. Transportation Research Part B: Methodological. 56, 136-160. http://dx.doi.org/10.1016/j.trb.2013.07.015

$\mathrm{Xu}$, S. X., Huang, G. Q., 2014. Efficient auctions for distributed transportation procurement. $\begin{array}{lllll}\text { Transportation Research Part B: } & \text { Methodological. 65. }\end{array}$ http://dx.doi.org/10.1016/j.trb.2014.03.005

Xu, S. X., Huang, G. Q., 2017. Efficient Multi - Attribute Multi - Unit Auctions for B2B E Commerce Logistics. Production and Operations Management. 26 (2), 292-304. https://doi.org/10.1111/poms.12638

Xu, S. X., Huang, G. Q., Cheng, M., 2016. Truthful, budget-balanced bundle double auctions for carrier collaboration. Transportation science. 51 (4), 1365-1386. https://doi.org/10.1287/trsc.2016.0694

Zhang, B., Ding, H., Li, H., Wang, W., Yao, T., 2014. A Sampling-Based Stochastic Winner Determination Model for Truckload Service Procurement. Networks and Spatial Economics. 14 (2), 159-181. https://doi.org/10.1007/s11067-013-9214-6

Zhang, B., Yao, T., Friesz, T. L., Sun, Y., 2015. A tractable two-stage robust winner determination model for truckload service procurement via combinatorial auctions. $\begin{array}{lllll}\text { Transportation Research Part B: } & \text { Methodological. 78, }\end{array}$ http://doi.org/10.1016/j.trb.2015.03.019

Zhang, M., Huang, G. Q., Xu, S. X., Zhao, Z., 2016. Optimization based transportation service trading in B2B e-commerce logistics. Journal of Intelligent Manufacturing. 1-17 (in press). https://doi.org/10.1007/s10845-016-1287-x 